\title{
Suppressor of Fused Controls Mid-Hindbrain Patterning and Cerebellar Morphogenesis via GLI3 Repressor
}

\author{
Jinny J. Kim, ${ }^{1,4}$ Paul S. Gill, ${ }^{1,5}$ Lianne Rotin, ${ }^{1}$ Matthijs van Eede, ${ }^{6}$ R. Mark Henkelman, ${ }^{2,6}$ Chi-Chung Hui, ${ }^{1,7}$ \\ and Norman D. Rosenblum ${ }^{1,3,4,5,8}$ \\ ${ }^{1}$ Program in Developmental and Stem Cell Biology, ${ }^{2}$ Program in Physiology and Experimental Medicine, and ${ }^{3}$ Division of Nephrology, The Hospital for Sick \\ Children, Toronto, Ontario M5G 1X8, Canada, and Departments of ${ }^{4}$ Physiology, ${ }^{5}$ Laboratory Medicine and Pathobiology, ${ }^{6}$ Medical Biophysics, ${ }^{7}$ Molecular \\ Genetics, and ${ }^{8}$ Paediatrics, University of Toronto, Toronto, Ontario M5S 1A8, Canada
}

Sonic Hedgehog and its GLI transcriptional effectors control foliation complexity during cerebellar morphogenesis by promoting granule cell precursor proliferation. Here, we reveal a novel contribution of Sonic Hedgehog-GLI signaling to cerebellar patterning and cell differentiation by generating mice with targeted deletion of Suppressor of Fused ( $\mathrm{SuFu}$ ), a regulator of Sonic Hedgehog signaling, in the mid-hindbrain. Postnatal SuFu-deficient mice exhibit impaired motor coordination and severe cerebellar mispatterning. SuFu conditional knock-out embryos display abnormal mid-hindbrain morphology associated with misexpression of $F g f 8$, and delayed differentiation and abnormal migration of major cerebellar cell types. Sonic Hedgehog is ectopically expressed in the external granule layer and Hedgehog signaling is upregulated. While expression of full-length GLI transcriptional activators downstream of Hedgehogs is markedly reduced, a processed form of GLI3, a transcriptional repressor, is essentially lost. Genetic expression of a Gli3 allele encoding GLI3 repressor in SuFu-deficient mice largely rescues abnormal cerebellar patterning and cell differentiation observed in mice with $\mathrm{SuFu}$ deficiency alone. Together, our data demonstrate that $\mathrm{SuFu}$ controls cerebellar patterning and cell differentiation in a GLI3 repressordependent manner.

\section{Introduction}

Cerebellar development is controlled by the state of Sonic Hedgehog $(\mathrm{SHH})$ signaling. Binding of SHH ligand to the transmembrane receptor PATCHED results in generation of full-length GLI transcriptional activators (GLI1, GLI2, GLI3) and inhibition of proteolytic processing of full-length GLI3 protein to a shorter form that acts as a transcriptional repressor. Absence of $\mathrm{SHH}$ signaling promotes formation of GLI3 repressor (GLI3R). The expression of $\mathrm{SHH}$ is low in the dorsal mid-hindbrain, from which the cerebellum is derived (Fuccillo et al., 2006). Accordingly, GLI3R levels are predicted to be relatively high. Indeed, GLI3R controls the domain of $F g f 8$ expression, which regulates both mid-hindbrain specification and the size of the midhindbrain (Aoto et al., 2002; Blaess et al., 2006, 2008). As the cerebellum develops, foliation is established by $\mathrm{SHH}$-dependent proliferation of granule cell precursors. High levels of SHH signaling are achieved at embryonic day 17 (E17) as Purkinje cells begin to secrete SHH (Corrales et al., 2006). Persistent SHH signaling results in uncontrolled proliferation of granule cell precursors and causes medulloblastoma, a cerebellar pediatric

Received April 27, 2010; revised Nov. 29, 2010; accepted Dec. 6, 2010

This work was supported by a Hospital for Sick Children Graduate Training Award (to J.J.K.) and a Canada Research Chair (to N.D.R.). We thank Andree Gauthier Fisher, David Tsui, Freda Miller, Jason Cain, and Lin Chen for technical assistance and helpful advice. We also thank Vijitha Thanabalasingam (Hui laboratory) for providing anti-SUFU antibody.

Correspondence should be addressed to Norman D. Rosenblum, Division of Nephrology, The Hospital for Sick Children, 555 University Avenue, Toronto, 0N M5G 1X8, Canada. E-mail: norman.rosenblum@sickkids.ca. DOI:10.1523/JNEUROSCI.2166-10.2011

Copyright $\odot 2011$ the authors $\quad 0270-6474 / 11 / 311825-12 \$ 15.00 / 0$ cancer (Dahmane and Ruiz i Altaba, 1999; Corrales et al., 2004, 2006; Lewis et al., 2004).

Suppressor of Fused (SUFU), an intracellular PEST-domaincontaining protein, was initially identified as a suppressor of Hedgehog (HH) signaling in Drosophila (Préat, 1992). Murine $\mathrm{SuFu}$ inactivation causes early embryonic lethality at E9.5 with cephalic and neural defects and ligand-independent activation of $\mathrm{HH}$ signaling similar to that observed in mice deficient in Patched1 (Ptc1), a negative regulator of HH signaling (Svärd et al., 2006). Moreover, SuFu functions as a tumor suppressor in medulloblastoma (Taylor et al., 2002; Lee et al., 2007). Biochemical analyses in mammalian cells have provided insight into mechanisms by which SUFU exerts its effects. SUFU prevents nuclear translocation of GLI1 and GLI2 and recruits GSK3 $\beta$ to promote proteolytic degradation of full-length GLI3 (Kogerman et al., 1999; Barnfield et al., 2005; Kise et al., 2009). SUFU also recruits the SAP18-mSin 3 histone deacetylase corepressor complex to GLI-binding regions within $\mathrm{HH}$ target promoters and represses transcription (Cheng and Bishop, 2002). Interestingly, recent data suggest that SUFU can also function to stabilize full-length GLI proteins by inhibiting SPOPdependent proteolytic degradation of full-length GLI proteins (Chen et al., 2009; Wang et al., 2010). Together, these observations indicate that SUFU may function in a dual capacity during SHH signal transduction to control both GLI activator and repressor function.

The early embryonic lethality observed in mice with germline inactivation of $S u F u$ has precluded analysis of $S u F u$ functions during cerebellar morphogenesis. To overcome this limitation, 


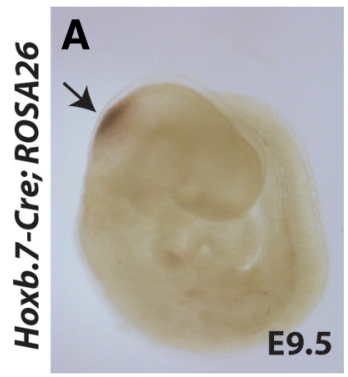

E13.5
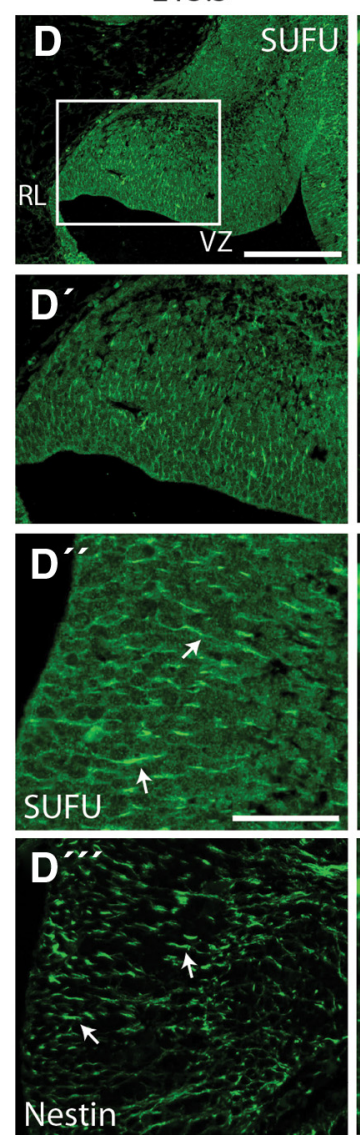

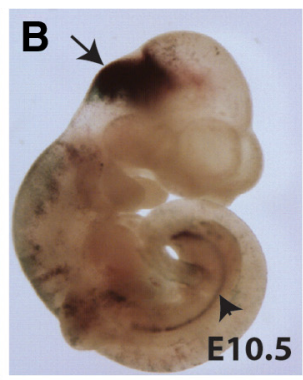

E10.5

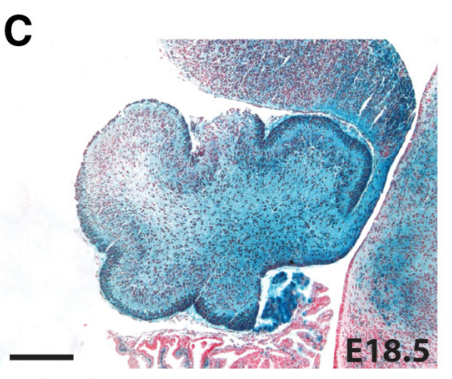

E18.5
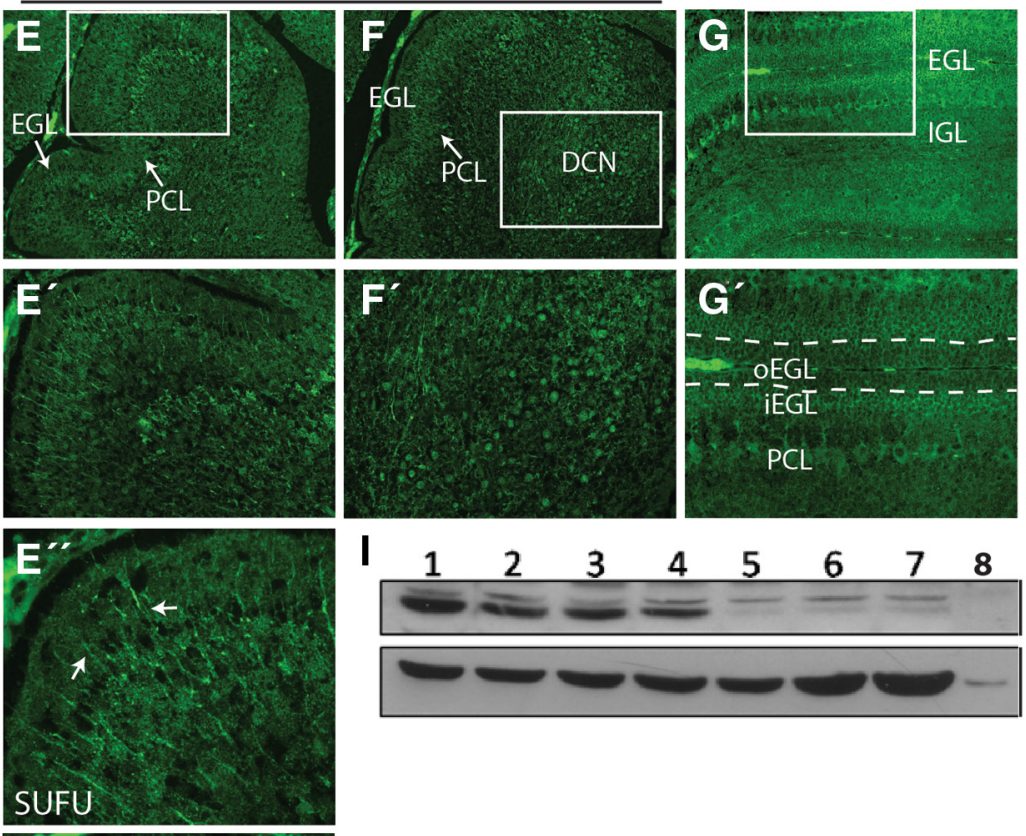

P21
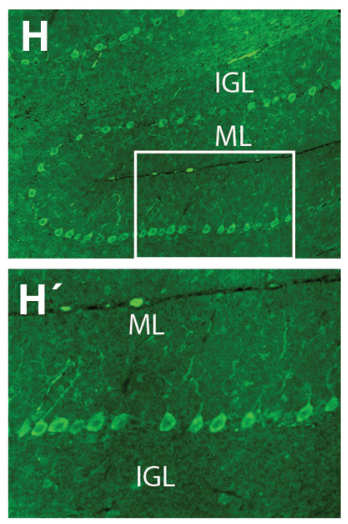

SUFU ACTIN

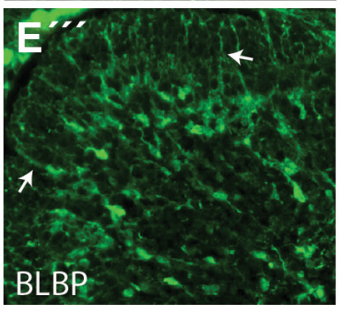

Figure 1. Hoxb.7-Cre is expressed in the mid-hindbrain and deletes SuFu in the cerebellum. $A, B, H o x b .7-C r e$ mice were crossed to ROSA26 mice to examine Cre expression. Hoxb.7 activates Cre in the mid-hindbrain at E9.5, before the onset of cerebellar morphogenesis $(\boldsymbol{A}) . \beta$-Galactosidase activity indicates Cre expression in the mid-hindbrain (arrows) and the Wolffian duct ( $\boldsymbol{B}$, arrowhead). C, Strong (re activity is detected in the cerebellum at E18.5. LacZ stain is denoted by blue stain and neutral red stain is denoted by pink stain. $\boldsymbol{D}-\boldsymbol{D}^{\prime \prime \prime}$, SUFU and Nestin, a specific marker of radial glia precursors, are expressed in an overlapping pattern in the ventricular zone of E13.5 wild-type cerebella (arrows, $\left.\mathbf{D}^{\prime \prime}, \boldsymbol{D}^{\prime \prime \prime}\right)$. $\boldsymbol{E}-\boldsymbol{E}^{\prime \prime \prime}$, At E18.5, SUFU is detected in the Purkinje cell layer (PCL) and is expressed in a pattern similar to that of Bergmann glia radial fibers, identified by BLBP expression ( $\boldsymbol{E}^{\prime \prime}, \boldsymbol{E}^{\prime \prime}$, arrows). $\boldsymbol{F}, \boldsymbol{F}^{\prime}$, SUFU is also observed in the presumptive deep cerebellar nuclei (DCN). $\boldsymbol{G}$, $\boldsymbol{G}^{\prime}$, The inner external granule layer (iEGL) and PCL express SUFU, whereas the outer EGL (OEGL) lacks SUFU expression at P6. $\boldsymbol{H}, \boldsymbol{H}^{\prime}$, SUFU is specifically expressed in Purkinje cells at P21. $\boldsymbol{I}$, Western

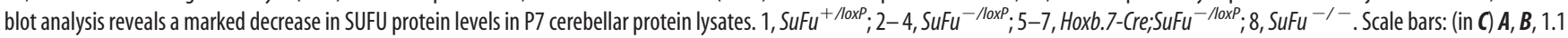
$\mathrm{mm} ; \boldsymbol{C}, 200 \mu \mathrm{m}$; (in $\boldsymbol{D}) \boldsymbol{D}-\boldsymbol{H}, 200 \mu \mathrm{m} ; \boldsymbol{D}^{\prime}-\boldsymbol{H}^{\prime}, 100 \mu \mathrm{m}$; (in $\left.\boldsymbol{D}^{\prime \prime}\right) \boldsymbol{D}^{\prime \prime}, \boldsymbol{D}^{\prime \prime \prime}, \boldsymbol{E}^{\prime \prime}, \boldsymbol{E}^{\prime \prime \prime}, 30 \mu \mathrm{m}$.

we used Cre recombinase (Cre)-mediated SuFu inactivation targeted to the cerebellum. Here, we demonstrate a novel role for SUFU in mid-hindbrain patterning, cell differentiation and regulation of SHH-GLI signaling during cerebellar development. Remarkably, cerebellar dysplasia observed in SuFu-deficient mice is largely dependent on expression of GLI3R.

\section{Materials and Methods}

Mice. SuFu ${ }^{\text {loxP }}$ (Chen et al., 2009) and Gli3 ${ }^{\Delta 699}$ (Böse et al., 2002) mice were maintained on a mixed background, and $\mathrm{SuFu}^{+/-}$(kindly provided by C.-C. Hui), Hoxb.7-Cre (Zhao et al., 2004), Ptcl $^{+/-}$(Goodrich et al., 1997) and $P t c 1^{\text {loxP }}$ (Ellis et al., 2003) mice were maintained on a CD1/129 background. ROSA $A^{\text {lacZ/lac } Z}$ mice (Soriano, 1999) were maintained on a C57BL/6 background. All animals were housed in the Animal Facility of the Hospital for Sick Children (Toronto, ON, Canada) and were genotyped by PCR as previously described (Böse et al., 2002; Zhao et al., 2004; Lee et al., 2007). Animal experiments were approved by the ethics committee at the Hospital for Sick Children.

Histology and immunohistochemistry. The noon of the day of a vaginal plug was used as E0.5 after fertilization. Embryos at various developmental stages were harvested from killed pregnant females, decapitated and fixed in 4\% paraformaldehyde (PFA) in PBS. Postnatal day 2 (P2)-P30 mice were killed by $\mathrm{CO}_{2}$ asphyxiation, and brains were dissected out and fixed in $4 \%$ PFA in PBS. Fixed tissues were embedded in paraffin for sectioning to prepare $5 \mu \mathrm{m}$ parasagittal sections on glass slides. Hematoxylin and eosin staining was performed to visualize cerebellum morphology. Immunofluorescence was performed on PFA- or formalinfixed, paraffin-embedded tissue sections using the following primary 

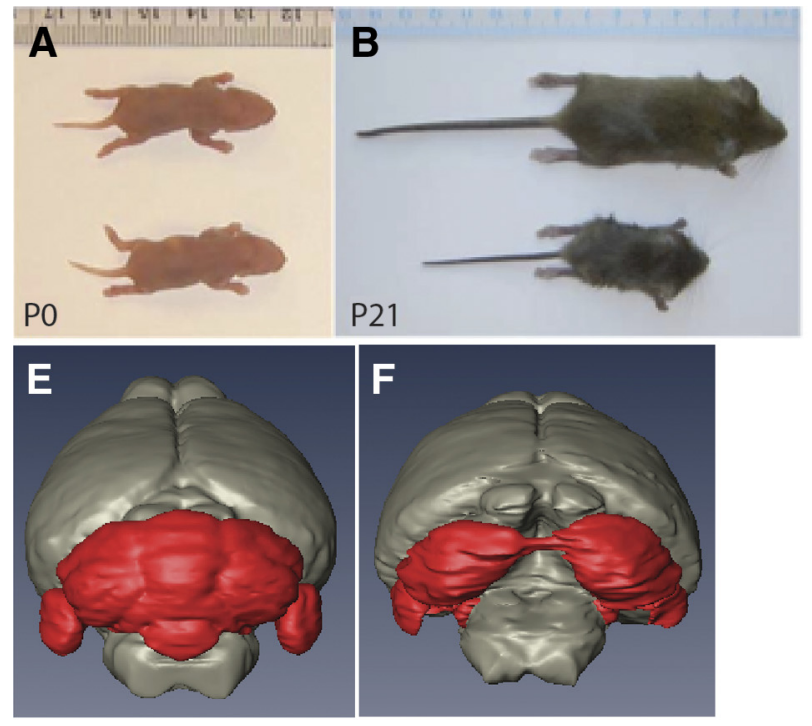

C
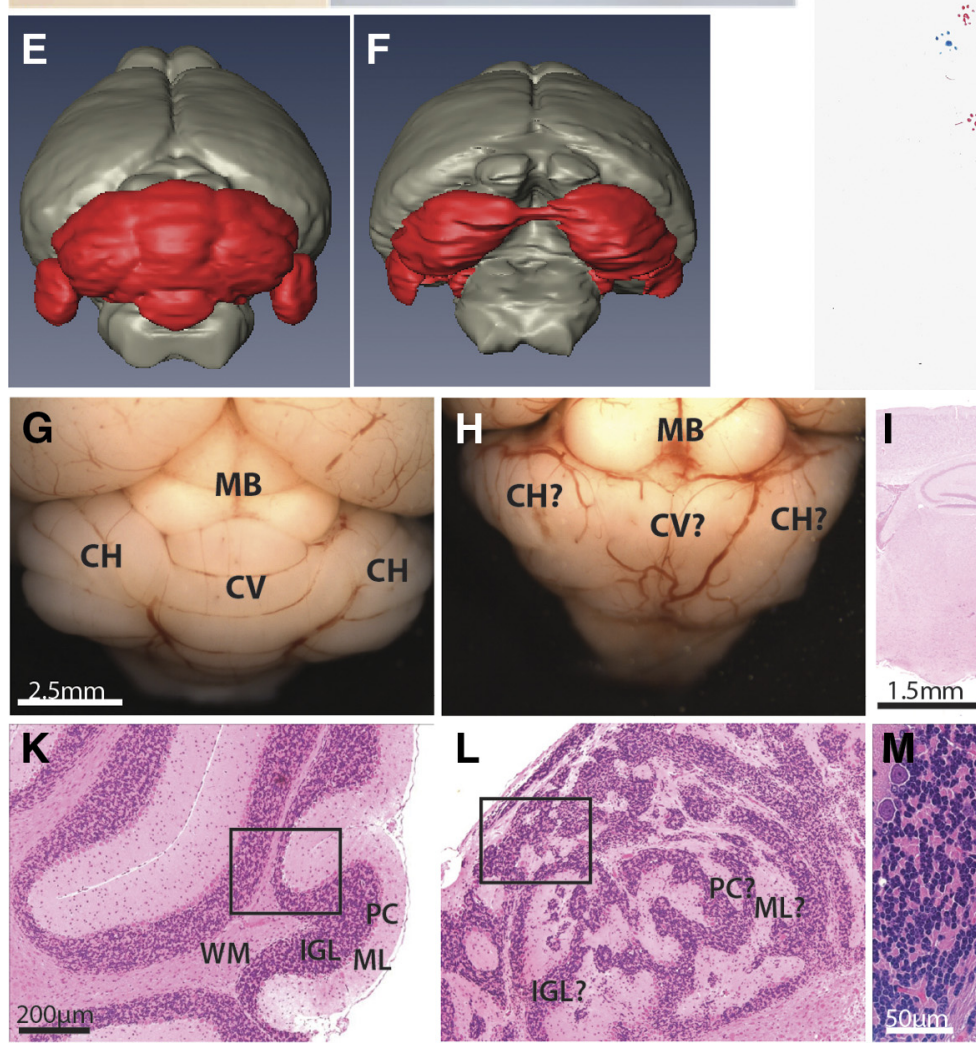

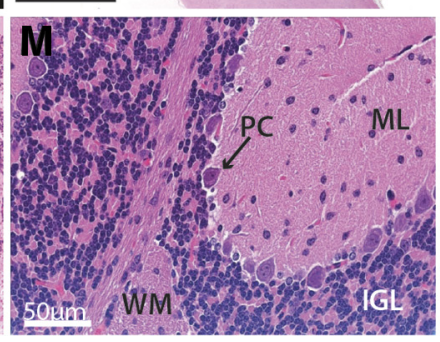

D
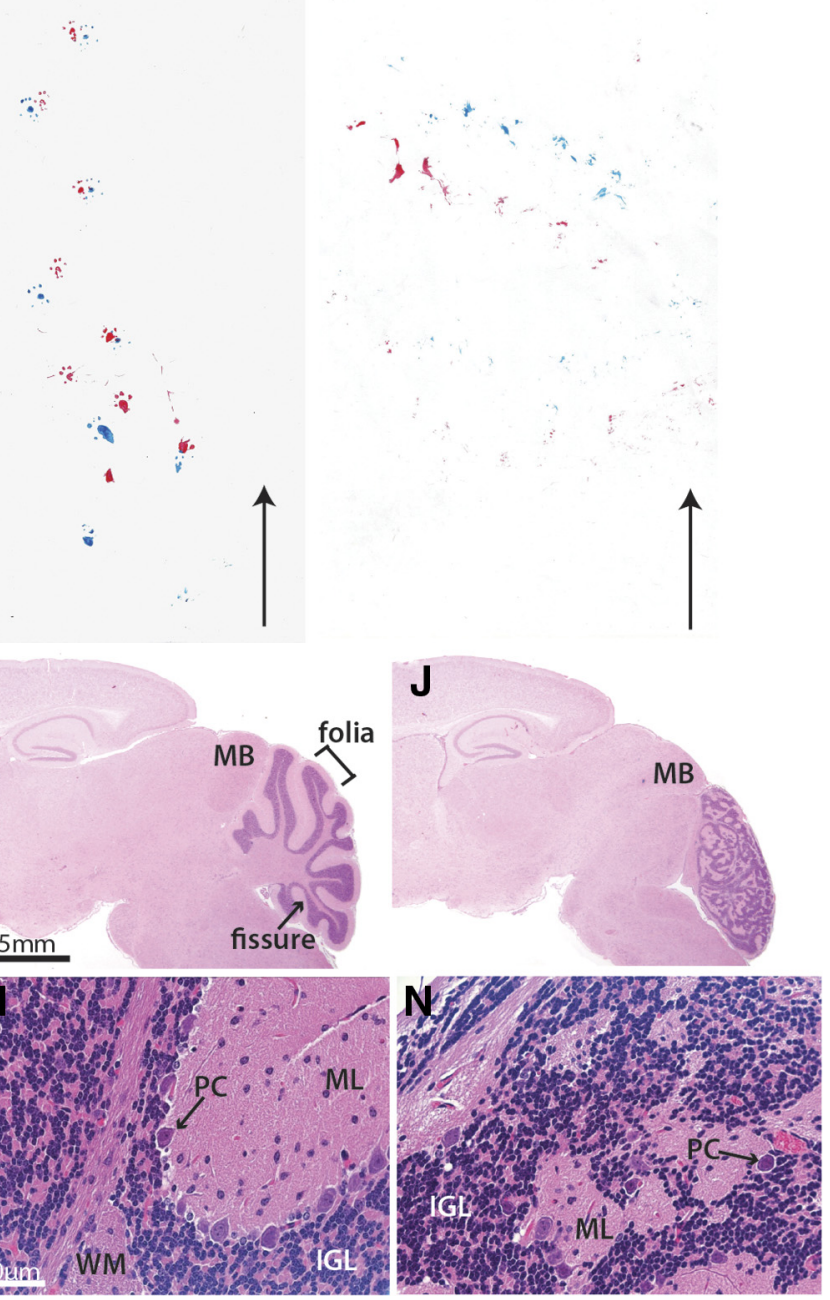

Figure 2. SUFU deficiency causes a severe reduction in body size, defective motor coordination and cerebellar mispatterning. $A, B, H o x b .7-C r e ; S u F u^{-/ l o x P}$ mutants display a reduction in body size, abnormal cerebellar morphology and defective patterning. Newborn Hoxb.7-Cre;SuFu ${ }^{-1 / 0 \times P}$ mutants are comparable to their control littermates in body size (A). Adult mutants display severe body size reduction (B).C, D, While P21 control mice display a normal gait marked by forefoot (red)-hindfoot (blue) coordination (C), Hoxb.7-Cre;SuFu ${ }^{-1 / 0 \times P}$ mutants display a severely ataxic gait, a sign of impaired motor coordination, characterized by an inability to walk forward (D). Arrows indicate the direction in which mice faced. $\boldsymbol{E}, \boldsymbol{F}, \mathrm{MRl}$ three-dimensional volume renderings of Hoxb.7-Cre; SuFu ${ }^{-1 / 0 \times P}$ mutant brains $(\boldsymbol{F})$ indicate severe abnormalities in cerebellar gross morphology (red) compared with control cerebella $(\boldsymbol{E})$. Note the hypoplastic or absent vermis in mutant cerebella. $\boldsymbol{G}$, $\boldsymbol{H}$, Hoxb.7-Cre;SuFu ${ }^{-110 \times P}$ cerebella $(\boldsymbol{H})$ are characterized by a lack of demarcation between the vermis and hemispheres and a lack of foliation. $\boldsymbol{I}, \boldsymbol{J}, \boldsymbol{H}$ Hematoxylin and eosin staining of control $(\boldsymbol{I})$ and mutant cerebella $(\boldsymbol{J})$ reveals severe cerebellar mispatterning marked by absence of distinct folia and fissures in mutant tissue at P21. $\boldsymbol{K}-\boldsymbol{N}$, Higher resolution imaging of control $(\boldsymbol{K}, \boldsymbol{M})$ and mutant cerebella $(\boldsymbol{L}, \boldsymbol{N})$ indicates cellular disorganization and abnormal cytoarchitecture in mutant tissue. MB, Midbrain; $\mathrm{CH}$, cerebellar hemisphere; $\mathrm{CV}$, cerebellar vermis; $\mathrm{ML}$, molecular layer; $\mathrm{PC}$, Purkinje cell; IGL, inner granule layer; WM, white matter (see also supplemental Movie S1, available at www.jneurosci.org as supplemental material).

antibodies: mouse anti-calbindin D28K (1:200, Sigma), rabbit anti-SUFU (1:1500, kindly provided by C.-C. Hui), rabbit anti-BLBP (brain lipidbinding protein) (1:200, Abcam), mouse anti-GFAP (1:200, Millipore), mouse anti-NeuN (1:100, Millipore), rabbit anti-Pax2 (1:200, Covance), rabbit anti-Pax6 (1:300, Covance), mouse anti-PCNA (proliferating cell nuclear antigen) (1:500, Cell Signaling Technology), rabbit anti-Nestin (1:500, Abcam), mouse anti-Ki67 (1:200, BD Biosciences), and mouse anti- $\beta$ III tubulin (1:400, Covance). Fluorescence detection was achieved by staining tissue sections with species-specific Alexa Fluor 488 and Alexa Fluor 568 secondary antibodies (1:500, Invitrogen) and counterstaining with $4^{\prime}, 6^{\prime}$ diamidino-2-phenylindole dihydrochloride (1:1000, Sigma). Immunohistochemistry experiments were performed using rabbit anti-calbindin D28K (1:1000, Millipore) and biotinylated secondary antibodies (ABC Kit, Vector Laboratories).

$\beta$-Galactosidase reporter assay. X-gal staining of whole embryos and whole brains was performed according to published methods (Cain et al., 2009). After staining, embryos were postfixed in 10\% formalin for paraffin embedding in paraffin, and whole embryos were photographed using a Leica EZ4D dissecting microscope. X-gal stained tissue sections were then counterstained with neutral red for nuclear staining.

In situ mRNA hybridization. In situ hybridization was performed on PFA-fixed and paraffin-embedded tissue sections as described previously (Mo et al., 1997) using digoxigenin-labeled RNA probes encoding Fgf8 (kindly provided by Lijun Chi, Hospital for Sick Children, Toronto, ON, Canada), Ptc1 (kindly provided by Andrew McMahon, Harvard University, Cambridge, MA), and Shh and Otx2 (kindly provided by C.-C. Hui).

Magnetic resonance imaging. $\mathrm{P} 21$ and $\mathrm{P} 30$ mice were anesthetized by injecting Rompun $(20 \mathrm{mg} / \mathrm{kg})$ and ketamine $(100 \mathrm{mg} / \mathrm{kg})$ intraperitoneally and underwent transcardiac perfusion with $4 \%$ PFA. They were subsequently decapitated. Magnetic resonance images were taken at $32 \mu \mathrm{m}$ isotropic resolution and analyzed.

Western blot. Whole-cell protein lysates were prepared from isolated postnatal day 7 mouse cerebellums by Dounce A homogenization in ice-cold radioimmunoprecipitation assay buffer $(50 \mathrm{~mm}$ Tris- $\mathrm{HCl} \mathrm{pH}$ 7.4, $1 \%$ Nonidet P-40, 0.5\% Na-deoxycholate, $150 \mathrm{~mm} \mathrm{NaCl}, 1 \mathrm{~mm}$ EGTA, and 5 mM EDTA) containing Protease Inhibitor Cocktail P8340 
(Sigma). Protein lysates were separated by SDSPAGE and transferred onto a polyvinylidene difluoride membrane. Following membrane blocking in 5\% nonfat dry milk, membranes were exposed to one of the following primary antibodies overnight at $4^{\circ} \mathrm{C}$ : rabbit $\alpha$-SUFU (1:5000 dilution; donated by C.-C. Hui), mouse $\alpha$-GLI1 (1: 3300 dilution; Abcam), rabbit $\alpha$-GLI2 (1:250 dilution; donated by C.-C. Hui), or rabbit $\alpha$-GLI3 H280 (1:250 dilution; Santa Cruz Biotechnology) antibody. Signal was detected using chemiluminescence (ECL Kit; GE Healthcare).

Cerebellar precursor isolation and culture. E12 wild-type and $S u F u$-deficient cerebella were microdissected in HBSS (Invitrogen) and finely minced in Neurobasal media containing $1 \% \mathrm{v} / \mathrm{v}$ penicillin/streptomycin, $2 \%$ B27 supplements, $500 \mu \mathrm{M}$ L-glutamine (all from Invitrogen) and $40 \mathrm{ng} / \mathrm{ml} \mathrm{FGF2} \mathrm{(Collaborative}$ Biomedical Products). Cerebella were triturated to single cell suspension and plated on chamber slides coated with $1 \%$ poly-D-lysine and $2 \%$ laminin (both from Collaborative Biomedical Products). Dissociated cells were grown at $37^{\circ} \mathrm{C}$ and $5 \% \mathrm{CO}_{2}$ for $3 \mathrm{~d}$ before immunostaining analysis according to standard protocols using antibodies listed above.

Statistics. Student's $t$ tests were applied to calculate SD and SE. Findings were determined to be significant if the $p$ value was $<0.05$. All data reported here are based on representative samples and an experimental $n \geq 3$.

\section{Results}

\section{Targeted deletion of $S u F u$ in the} mid-hindbrain

Since SuFu-null mutants exhibit early embryonic lethality (E9.5) (Svärd et al., 2006), we generated conditional knockout mice (Hoxb.7-Cre;SuFu ${ }^{-/ l o x P}$ ) using Cre recombinase under the control of the Hoxb.7 promoter. We identified the spatial location of Hoxb.7-Cre expression at the onset of cerebellar morphogenesis (between E9.5 and E10.5) using the ROSA reporter gene. Cre expression, assayed by $\beta$-galactosidase activity, was detected as early as E9.5 in the mid-hindbrain region including rhombomere 1 and was also observed in the Wolffian duct and the dorsal root ganglia, as previously reported (Zhao et al., 2004) (Fig. 1A,B). Cre recombinase activity was detected in all cells of the developing cerebellum (Fig. 1C). SUFU expression during normal cerebellar development was defined by immunostaining using specific anti-SUFU antibodies. SUFU was strongly expressed in ventricular zone precursors at E13.5 (Fig. 1D, $D^{\prime}$ ). The spatial expression pattern of SUFU was comparable to that of Nestin, a marker of radial glia precursors (Fig. $\left.1 D^{\prime \prime}, D^{\prime \prime \prime}\right)$. Both Nestin and SUFU are expressed in fibers throughout the ventricular zone. At E18.5, SUFU expression was observed in the location of the Purkinje cell layer, Bergmann glia fibers and deep cerebellar nuclei (Fig. $\left.1 E, E^{\prime}, F, F^{\prime}\right)$. Moreover, SUFU is expressed in a pattern highly similar to that of Bergmann glia, marked by BLBP (Fig. $\left.1 E^{\prime \prime}, E^{\prime \prime \prime}\right)$ consistent with its expression in radial glia precursors at E13.5. At P6, during the period of granule cell precursor proliferation, the outer external granule layer (EGL) lacked SUFU expression. In contrast, SUFU was expressed in both the inner EGL and Purkinje cell layer (Fig. $1 G, G^{\prime}$ ). In the adult cerebellum
(P21), SUFU expression was restricted to Purkinje cells (Fig. $\left.1 \mathrm{H}, \mathrm{H}^{\prime}\right)$. SUFU deficiency was confirmed in Hoxb.7-Cre;SuFu ${ }^{-/ l o x P}$ mice using Western analysis and cerebellar protein lysates (Fig. $1 I$ ). In contrast to wild-type controls (Fig. $1 I$, lanes 1-4), SUFU protein was barely detectable in cerebellar lysates from Hoxb.7$\mathrm{Cre} ; \mathrm{SuFu} u^{-/ l o x P}$ mice (Fig. 1I, lanes 5-7) and was only slightly greater in quantity than that observed in $S u F u$ germline knockout embryo lysates (Fig. 1I, lane 8). Residual amounts of SUFU in Hoxb.7-Cre;SuFu ${ }^{- \text {lloxP }}$ mice is likely due to incomplete deletion of $\mathrm{SuFu}$ in some cells.

\section{Loss of SUFU results in cerebellar dysfunction and severe patterning defects}

Hoxb.7-Cre;SuFu ${ }^{-/ l o x P}$ pups were comparable to control littermates at $\mathrm{P} 0$ in both gross anatomical appearance and body size (Fig. 2A). However, by P21 mutant mice demonstrated severe runting and most mutants failed to survive the first month of life (Fig. $2 B$ ). The presence of milk in the stomach of mutant pups and their capacity to consume food left on the bottom of their cage postweaning (data not shown) strongly suggested that runting was not due to decreased food intake. Interestingly, Hoxb.7$\mathrm{Cre} ; \mathrm{SuFu}^{-/ l o x P}$ mutants exhibited significantly impaired motor 


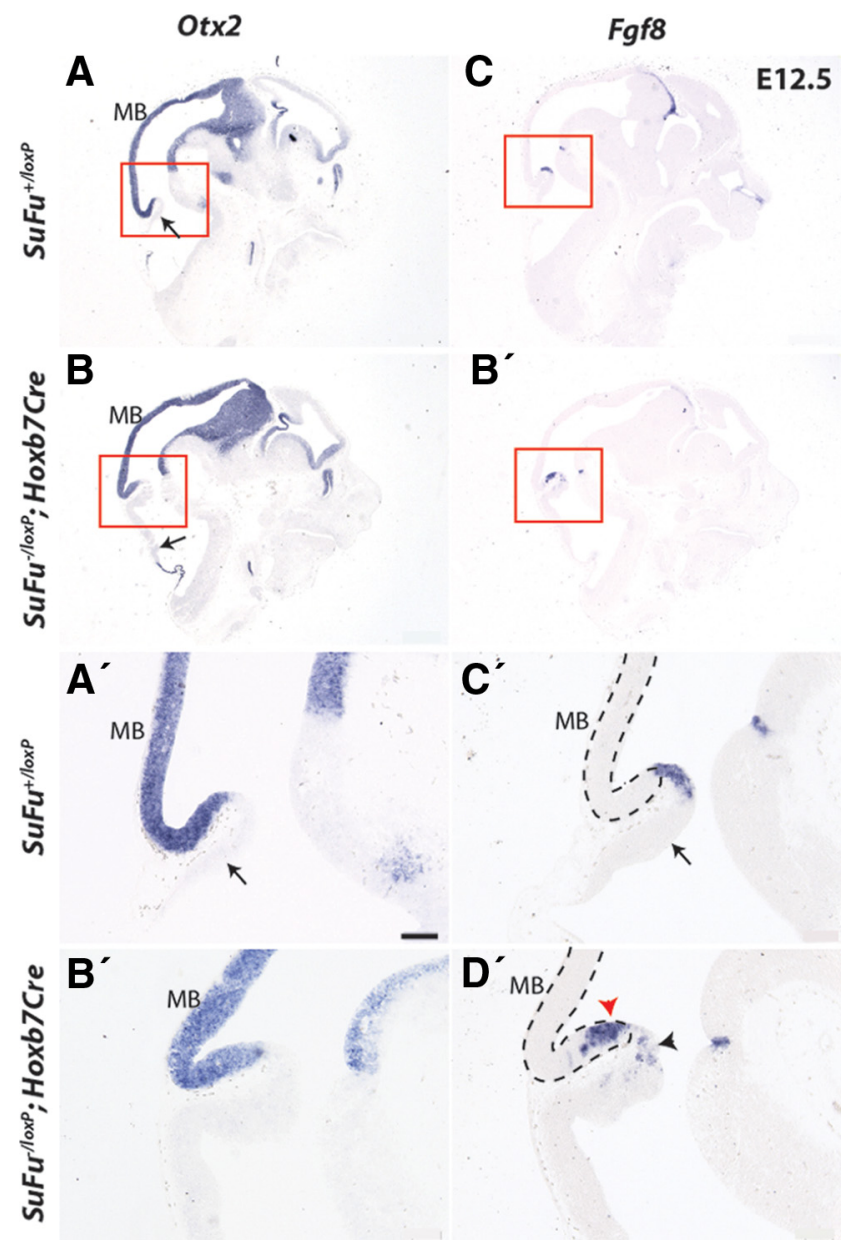

Figure 4. Loss of SUFU causes abnormal mid-hindbrain patterning. $\boldsymbol{A}, \boldsymbol{B}, 0$ tx2 marks the midbrain (MB) in control and Hoxb.7-Cre;SuFu ${ }^{-1 / 0 x P}$ embryos at E12.5. Note the anterior shift of the posterior limit of Otx2 expression in Hoxb.7-Cre;SuFu ${ }^{-1 / 0 x P}$ mutants. Arrows indicate the presumptive cerebellar primordium. Areas demarcated by rectangles are shown at a higher magnification in $\boldsymbol{A}^{\prime}-\boldsymbol{D}^{\prime}$. C, D, Fgf8 expression is detected in a narrow band at the boundary of the midbrain and the cerebellar primordium. In Hoxb.7-Cre;SuFu ${ }^{-/ l o x P}$ mutants, Fgf8 expression is shifted in an anterior manner. $\boldsymbol{A}^{\prime}-\boldsymbol{D}^{\prime}$, While 0 tx2 and Fgf8 expression domains do not overlap and have sharp boundaries in control embryos, a significant overlap (red arrowhead) is observed due to the anterior shift of Fgf8 expression in Hoxb.7-Cre;SuFu-/loxP mutants. Fgf8 expression in the nonoverlapping region (black arrowhead) is weak and lacks sharp boundaries. Dashed line outlines the expression domain of Otx2. Scale bars: (in $A^{\prime}$ ) $\boldsymbol{A}-\boldsymbol{D}, 800 \mu \mathrm{m} ; \boldsymbol{A}^{\prime}-\boldsymbol{D}^{\prime}$, $200 \mu \mathrm{m}$.

coordination that resulted in an abnormal gait and a failure to walk forward (Fig. 2C,D; supplemental Movie S1, available at www.jneurosci.org as supplemental material). Consistent with these findings, magnetic resonance imaging (MRI) demonstrated that Hoxb.7-Cre;SuFu ${ }^{-/ l o x P}$ cerebella displayed abnormal gross anatomical morphology characterized by an absent or hypoplastic vermis and lack of normal foliation (Fig. 2E,F). Gross morphological analysis of Hoxb.7-Cre;SuFu ${ }^{- \text {loxP }}$ mutant cerebella revealed lack of normal foliation pattern and clear demarcation between the vermis and the lateral hemispheres (Fig. 2G,H). Furthermore, compared with control brains, the superior and inferior colliculi of Hoxb.7-Cre;SuFu ${ }^{-/ l o x P}$ mutants appeared hyperplastic. Histological analysis demonstrated lack of folia and distinct cellular layers that characterize control cerebella (Fig. $2 I, J)$. Moreover, in contrast to the normal cerebellum which consists of a Purkinje cell monolayer and an inner granule layer (Fig. $2 K, M$ ), in mutant mice both granule cells and Purkinje cells were randomly localized in cellular aggregates (Fig. $2 L, N$ ). Together, these data demonstrate a requirement for $\mathrm{SuFu}$ during cerebellar morphogenesis.

\section{SUFU deficiency causes abnormal mid-hindbrain patterning and delayed cerebellar formation}

To determine the embryonic origins of the postnatal cerebellar phenotype, we examined control and Hoxb.7-Cre;SuFu ${ }^{-/ l o x P}$ embryos at various stages of cerebellar morphogenesis. At E13.5, when a thickened cerebellar primordium is clearly visible in control embryos, no such structure was detected in Hoxb.7-Cre; $S u F u^{-/ l o x P}$ mutants (Fig. $3 A, B$ ). A significant overgrowth and expansion of the isthmic tissue was observed in mutant embryos, which led to truncation of the midbrain. This tissue overgrowth between the cerebellar primordium and inferior colliculus was determined to be isthmic based on the lack of cerebellum-specific cell marker expression, such as calbindin and PAX6, and the failure of the EGL to extend into the isthmic region (see Fig. 5). Interestingly, conditional knock-out of Ptc1 using Hoxb.7-Cre mice at E13.5 resulted in severe overgrowth of the mid-hindbrain without delayed cerebellar formation or apparent defects in anterior-posterior patterning in $67 \%$ of all mutants examined ( 4 of 6 ) at E13.5 (supplemental Fig. S1 $A-C$, available at www.jneurosci.org as supplemental material). In $33 \%$ of mutants ( 2 of 6 ), exencephaly was detected caused by an open neural tube defect in the region of dorsal mid-hindbrain. Thus, in contrast to Ptcl, SuFu controls anteriorposterior patterning of the mid-hindbrain.

An EGL was detected in E15.5 control embryos as granule cell precursors migrate from the rhombic lip over the dorsal surface of the cerebellar primordium (Fig. 3C). Although an EGL was detected in Hoxb.7-Cre;SuFu ${ }^{- \text {lloxP }}$ mutants, it failed to extend from the rhombic to the isthmus-cerebellum junction. Further, the rhombic lip was larger compared with that of control embryos, indicating delayed granule cell migration from the rhombic lip (Fig. 3D). In addition, the isthmic overgrowth was dramatically increased in size, forming large folds of neural tissue between the midbrain and the cerebellar primordium and resulting in persistent truncation of the midbrain. By E18.5, distinct cell layers and foliation were observed in control cerebella as Purkinje cells formed a monolayer beneath the EGL (Fig. 3E). However, in Hoxb.7-Cre;SuFu ${ }^{-/ l o x P}$ cerebella, there was a lack of distinct cell layers and foliation (Fig. $3 F$ ). Together, these observations demonstrate that abnormalities caused by SUFU deficiency arise early during mid-hindbrain patterning and delay the onset of cerebellar formation.

\section{Fgf8 expression is abnormal in the absence of $S u F u$}

Mid-hindbrain structures are characterized by the expression of transcription factors and secreted factors that are generated by the isthmic organizer. To elucidate the mechanism by which abnormal mid-hindbrain morphology is generated in SuFudeficient mice, we performed in situ hybridization to investigate specification of specific regions of the mid-hindbrain. In both control and Hoxb.7-Cre;SuFu ${ }^{-1 / o x P}$ embryos, Otx2 marked the entire midbrain with a sharp boundary at the isthmus (Fig. $\left.4 A, A^{\prime}, B, B^{\prime}\right)$. While the $F g f 8$ expression domain in control embryos marked the junction between the midbrain and the cerebellar primordium with sharp boundaries, $F g f 8$ expression was shifted in an anterior manner in Hoxb.7-Cre;SuFu ${ }^{-l l o x P}$ mutants (Fig. 4C,D). As a result, although $O t x 2$ and Fgf8 expression domains do not overlap in wild-type embryos, a significant overlap of the two expression domains occurred in Hoxb.7-Cre;SuFu ${ }^{- \text {lloxP }}$ mutants (Fig. $4 C^{\prime}, D^{\prime}$ ). Furthermore, $F g f 8$ expression detected in 

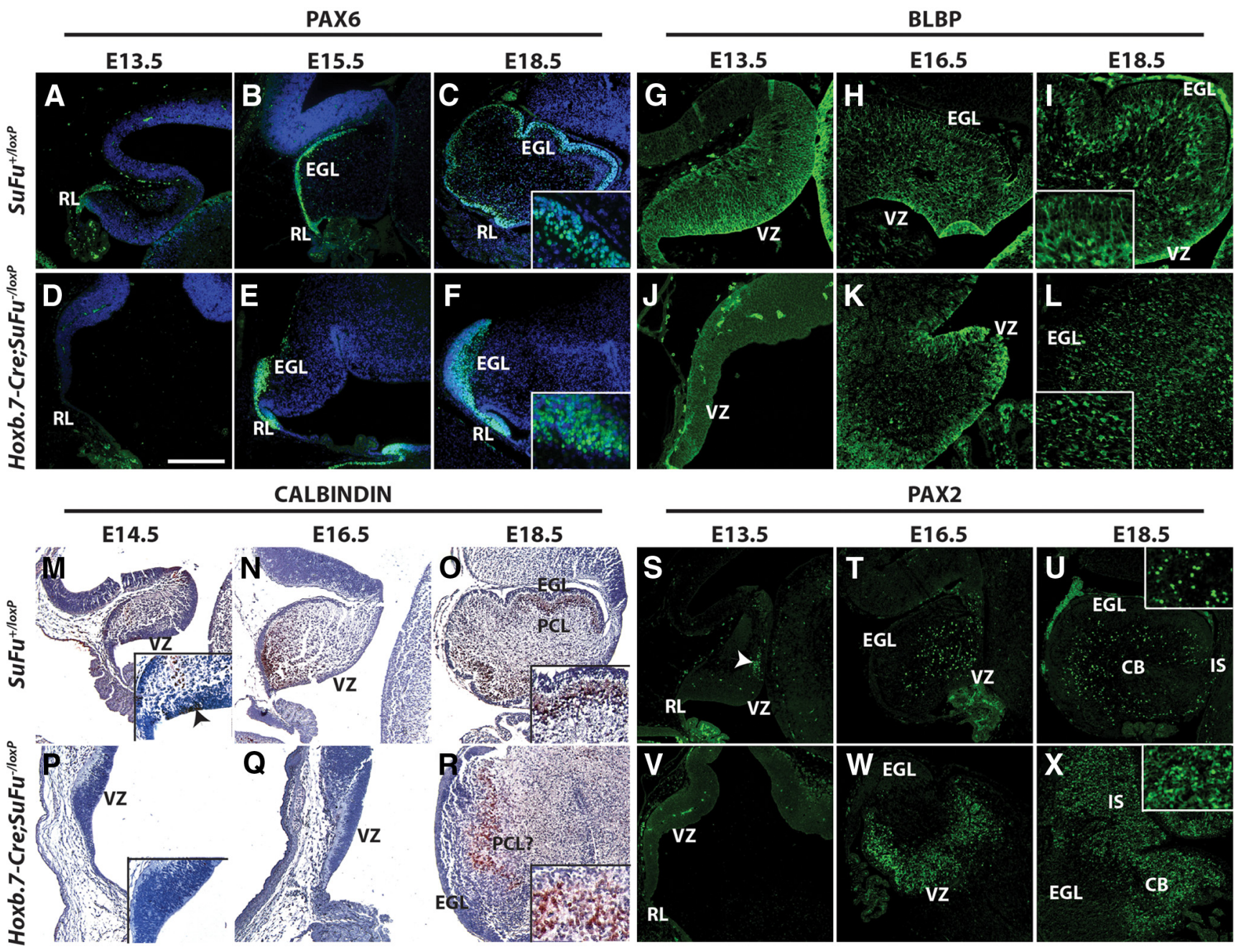

PAX2

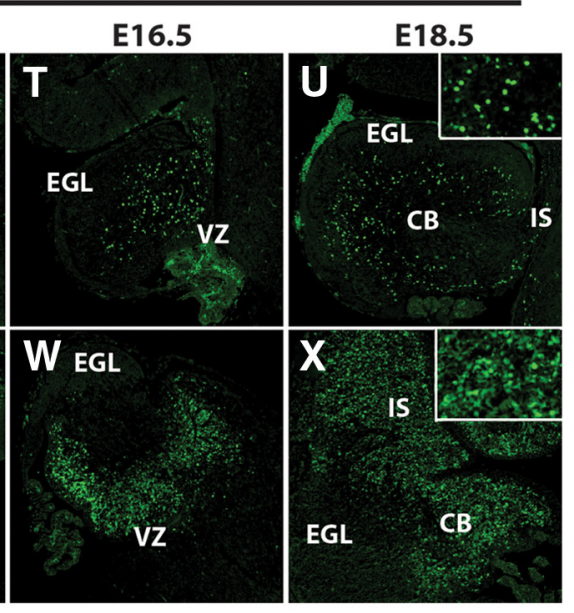

Figure 5. Cerebellar cell differentiation and migration is abnormal in the absence of SuFu. A-F, PAX6 staining reveals that Hoxb.7-Cre;SuFu-MoxP granule cell precursors are delayed in cell specification and form a defective EGL. G-L, As marked by BLBP, Bergmann glia arise from the ventricular zone (VZ) late and display abnormal migration and disorganization in Hoxb.7-Cre;SuFu ${ }^{-/ 10 \times P}$ mutants. $\boldsymbol{M}-\boldsymbol{R}$, Calbindin-expressing Purkinje cell precursors in Hoxb.7-Cre;SuFu ${ }^{-1 / 0 \times P}$ cerebella are delayed in specification and fail to form a thin layer underneath the granule cells. Note that the number of Purkinje cells is markedly reduced compared with that of control cerebella. $S-X$, PAX2 staining demonstrates that GABAergic interneuron precursors in mutant cerebella exhibit a delay in cell specification and are significantly increased in number compared with control cerebella. Also, ectopic localization of interneuron precursors is detected in the isthmus (IS) at E18.5. CB,

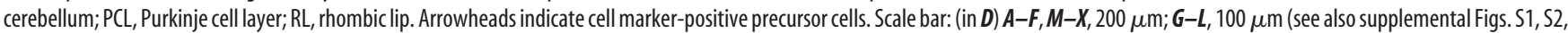
available at www.jneurosci.org as supplemental material).

the nonoverlapping region was markedly reduced and lacked clear boundaries that demarcate its expression domain. This abnormal expression of mid-hindbrain markers suggested that $\mathrm{SuFu}$ controls proper specification of distinct neural compartments during mid-hindbrain patterning.

\section{$S u F u$ deficiency delays cerebellar cell differentiation}

To investigate the effect of $S u F u$ deficiency on cell differentiation, we studied expression of markers of cerebellar cell types. Marked by PAX6, granule cell precursors arise from the rhombic lip at E13.5, and subsequently form the EGL over the surface of the cerebellum (Fig. $5 A-C$ ). Granule cell precursors were absent in Hoxb.7-Cre;SuFu ${ }^{-/ \text {loxP }}$ mutants at E13.5 (Fig. 5D). Although the EGL was detected at later embryonic stages in mutant mice, it failed to form a thin layer of cells over the dorsal surface of the cerebellar primordium (Fig. $5 E, F$ ). In addition, the rhombic lip was enlarged compared with control cerebella. BLBP-expressing Bergmann glia, specialized radial glia found in the cerebellum, normally arise from the ventricular zone at E13.5 and migrate toward the EGL to form a layer with Purkinje cells (Fig. 5G-I).
However, Bergmann glia were not detected in Hoxb.7-Cre; $\mathrm{SuFu} u^{-/ l o x P}$ cerebella at E13.5 (Fig. 5J). Interestingly, Bergmann glia were localized in the ventricular zone at E16.5 when they normally migrate toward the EGL (Fig. $5 K$ ). These cells failed to form a layer and were severely disorganized and ectopic at E18.5 in mutant cerebella (Fig. $5 \mathrm{~L}$ ). In contrast, BLBP-expressing radial glia precursors were detected in Hoxb.7-Cre;Ptc1 ${ }^{- \text {IloxP }}$ embryos at E13.5, suggesting a role for $S u F u$ in cell differentiation that is distinct from that of Ptc1 (supplemental Fig. S1D, available at www.jneurosci.org as supplemental material). Similar to Bergmann glia, Purkinje cells, marked by calbindin, were detected in the ventricular zone at E14.5 in control cerebella (Fig. 5M). Purkinje cell migration and the formation of a Purkinje cell layer beneath the EGL was observed by E18.5 (Fig. $5 \mathrm{~N}, \mathrm{O}$ ). In contrast, Purkinje cells were absent at E14.5 and E16.5 in Hoxb.7-Cre; $S u F u^{- \text {lloxP }}$ mutants (Fig. 5P,Q). While Purkinje cells were detected in a region underlying the EGL at E18.5, the number of Purkinje cells was decreased compared with control cerebella (Fig. $5 R$ ). GABAergic interneuron precursors, marked by PAX2 expression, were detected as early as E13.5 in control cerebella and were 

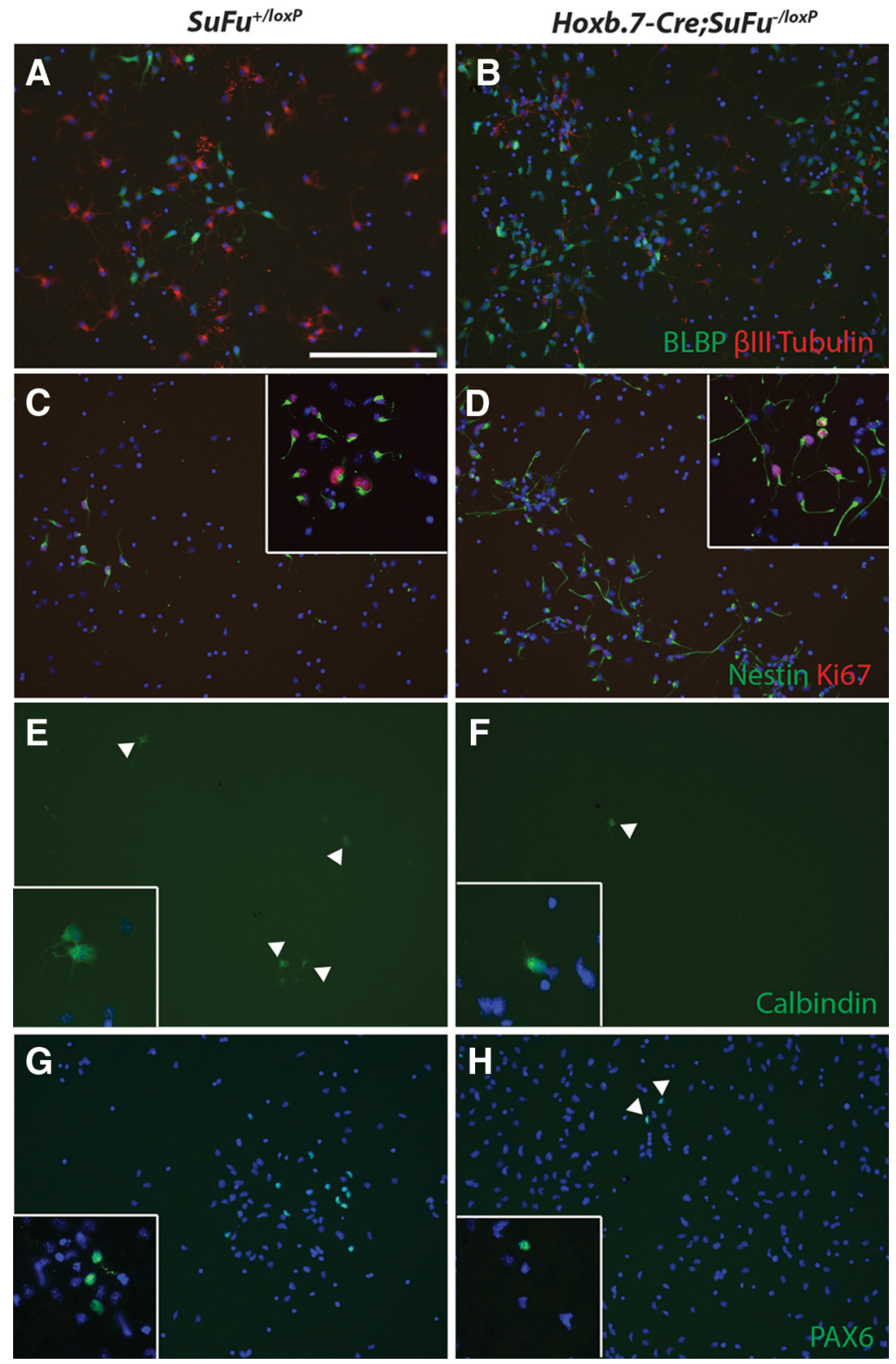

Figure 6. SuFu-deficient cells undergo enhanced gliogenesis and are delayed in neuronal differentiation. $A, B$, Double staining of BLBP (green) and $\beta \| I I$ tubulin (red) demonstrates that the proportion of BLBP-expressing cells versus $\beta$ III tubulin cells is significantly increased in Hoxb.7-Cre;SuFu-1loxP cerebellar cultures (control: $0.53 \pm 0.08$; mutant: $3.00 \pm 0.45, p<0.001$ ). C, D, Nestin-positive cells (green) coexpress Ki67 (red), and the proportion of Nestin- and Ki67-positive cells is significantly upregulated in Hoxb.7-Cre;SuFu ${ }^{-10 \times P}$ cerebellar cultures (control: $32.0 \pm 3.47 \%$; mutant: $74.4 \pm 3.46 \%, p<0.0001$ ). Note that the neuronal processes, as visualized by Nestin staining, are markedly longer in $H_{0 x b .7-C r e ; S u F u^{-110 \times P}}$ cells (insets). $\boldsymbol{E}, \boldsymbol{F}$, Fewer calbindinpositive cells (arrowheads) are detected in Hoxb.7-Cre;SuFu-lloxP cerebellar cultures compared with control cultures. G, H, PAX6 expression (arrowheads) is decreased in Hoxb.7-Cre;SuFu-10xP cultures. Scale bar, $200 \mu \mathrm{m}$.

located diffusely throughout the mantle zone of the cerebellum by E18.5 (Fig. 5S-U). In contrast, while PAX2 expression was undetectable at E13.5 in Hoxb.7-Cre;SuFu ${ }^{-1 \text { lox }}$ mutants, the distribution and number of PAX2-positive cells was dramatically expanded at E16.5 and E18.5, extending rostrally into the isthmus (Fig. $5 \mathrm{~V}-\mathrm{X}$ ). Quantitative analysis of PAX2-positive cells revealed an $\sim 3$-fold increase in the number of GABAergic interneuron precursors in $\mathrm{SuFu-}$ deficient cerebella $\left({ }^{*} p=0.01\right.$; supplemental Fig. S2A, available at www.jneurosci.org as supplemental material). Collectively, these findings suggest that $S u F u$ plays an important role in the temporal regulation of cell differentiation.

To determine whether SUFU controls precursor cell fate or the timing of terminal cell differentiation, we isolated cerebellar pre- cursors from E12 embryos and cultured cells in vitro. Double staining with BLBP and $\beta$ III tubulin, markers of glial precursors and neurons, respectively, $3 \mathrm{~d}$ postplating, revealed a sixfold increase in the proportion of BLBP-positive cells versus $\beta$ III tubulin in cell cultures derived from Hoxb.7-Cre; $\mathrm{SuFu}{ }^{-1 \text { loxP }}$ cerebellar tissue compared with wild-type cerebellar cultures (control: $0.53 \pm 0.08$; mutant: $3.00 \pm 0.45,{ }^{*} p<$ 0.001 , Fig. $6 A, B)$. Consistent with the fact that BLBP marks radial glia precursor cells, both Nestin and Ki67 were significantly upregulated in Hoxb.7-Cre;SuFu ${ }^{-/ l o x P}$ cultures, as indicated by a 2.3 -fold increase in the proportion of Nestin- and Ki67-positive cells (control: $32.0 \pm 3.47 \%$; mutant: $74.4 \pm$ $3.46 \%,{ }^{\star} p<0.0001$, Fig. $\left.6 C, D\right)$. In parallel, neuronal cells, marked by calbindin and PAX6, were decreased in Hoxb.7-Cre; $S u F u^{-/ l o x P}$ cultures (Fig. 6E-H). Thus, loss of SUFU leads to enhanced gliogenesis at the expense of neurogenesis and causes a delay in neuronal differentiation.

\section{SUFU deficiency results in aberrant SHH signaling and decreased GLI proteins}

Since $\mathrm{SuFu}$ is implicated in $\mathrm{HH}$ signaling as a mediator of proteolytic processing of GLI activators into repressors, we investigated the state of $\mathrm{SHH}$ signaling activity in the absence of SUFU. At the onset of SHH signaling activation in the cerebellum (E17), weak Ptcl expression, a marker of $\mathrm{SHH}$ signaling activity, was detected in the EGL (Fig. 7A). In Hoxb.7-Cre;SuFu-/loxP mutants, significant upregulation and ectopic expression of Ptcl were observed in the EGL and in the ventricular zone, respectively, indicating an increase in the number of cells responsive to $\mathrm{SHH}$ signal (Fig. 7B). To determine the ability of mutant Purkinje cells to generate $\mathrm{SHH}$, we examined expression of Shh mRNA in E18.5 cerebella. Interestingly, while Shh expression was observed in the Purkinje cell layer in control cerebella, Shh was misexpressed in the EGL and absent in the Purkinje cell layer in Hoxb.7-Cre;SuFu ${ }^{-/ l o x P}$ cerebella (Fig. $7 C, D$ ). These findings indicate that granule cell precursors, in the absence of SUFU, aberrantly express Shh and upregulate their response to $\mathrm{SHH}$ signaling. Consistent with this overactivation of $\mathrm{SHH}$ signaling, cell proliferation, as assayed by PCNA staining, was markedly increased in Hoxb.7-Cre;SuFu ${ }^{-1 \text { loxP }}$ mutants at E18.5 (supplemental Fig. S3, available at www. jneurosci.org as supplemental material). Consistent with these results and contrasted with controls, expression of Gli3 was absent in the EGL in Hoxb.7-Cre;SuFu ${ }^{-1 / o x P}$ cerebella at E18.5 (Fig. 7 E, F). Interestingly, by P6, Gli3 expression in the outer EGL was similar in Hoxb.7-Cre; $\mathrm{SuFu}{ }^{-1 l o x P}$ cerebella (Fig. $7 \mathrm{H}$ ) compared with controls (Fig. 7G). Next, we examined the effect of SUFU deficiency on GLI protein levels. Western blot analysis revealed that levels of 

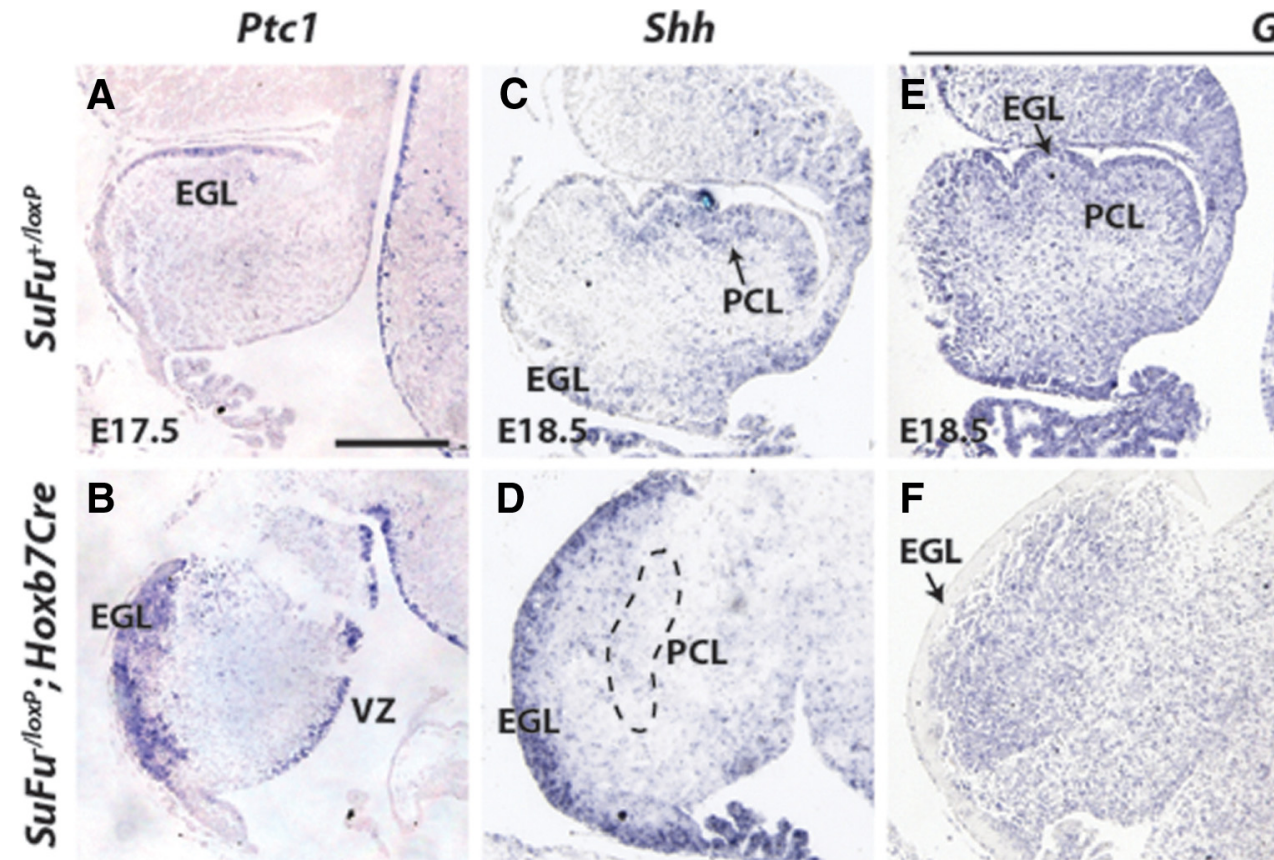

Gli3
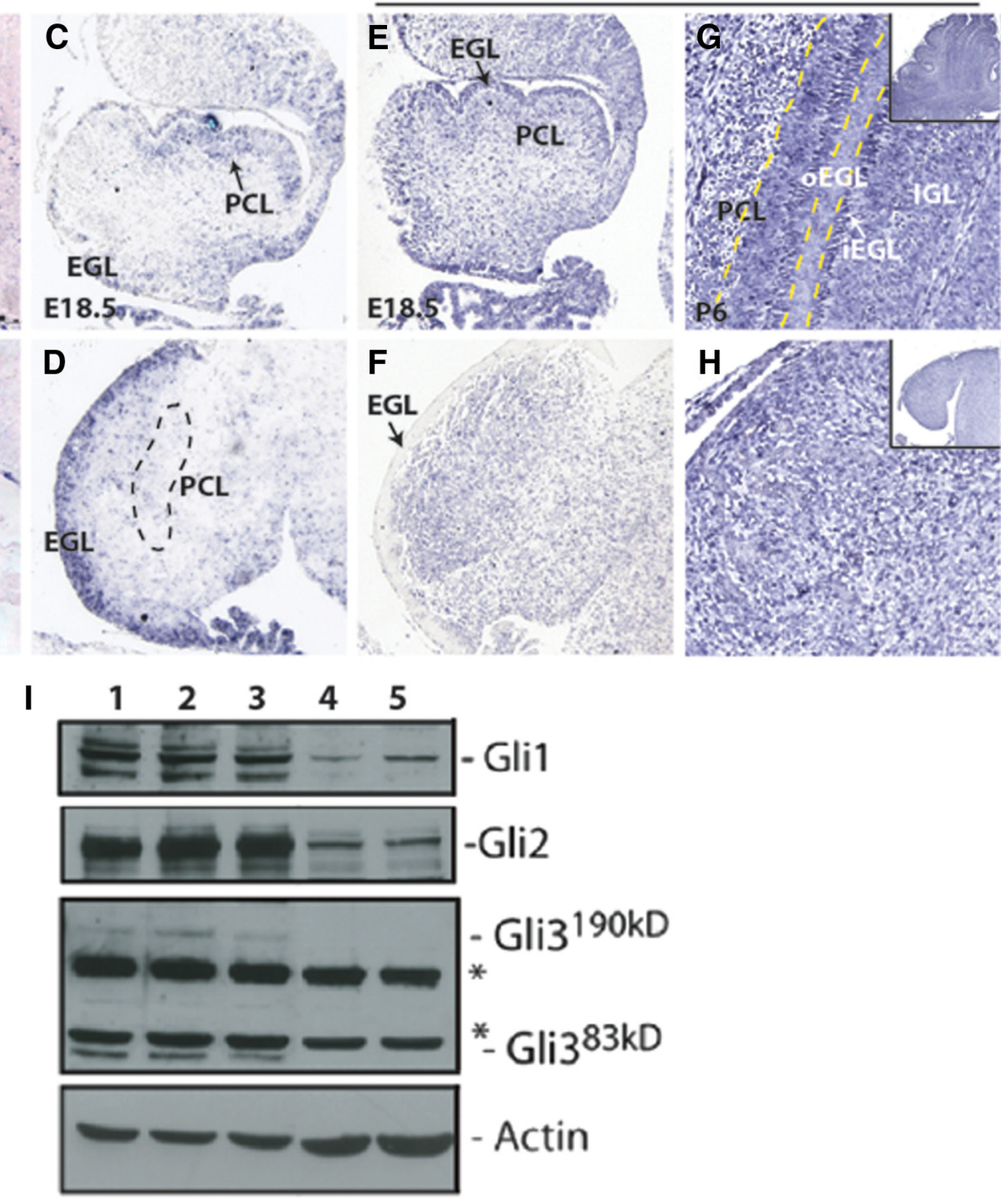

Figure 7. Loss of SUFU leads to upregulation and misexpression of SHH signaling activity and decreased levels of GLI proteins. A, B, mRNA in situ hybridization shows weak expression Ptc1, a readout of SHH signaling in the EGL in E17.5 control cerebella $(\boldsymbol{A})$. In contrast, Hoxb.7-Cre;SuFu ${ }^{-1 / 0 x P}$ cerebella display upregulation of Ptc1 and ectopic expression in the ventricular zone (VZ) (B). $\boldsymbol{C}$, D, Shh is detected in the Purkinje cell layer (PCL) and weakly in the EGL in control cerebella at E18.5 (C). In the absence of SUFU, Shh is absent in the PCL (dashed line) and misexpressed by the EGL (D). E, F, Gli3 mRNA expression is absent in the EGL in Hoxb.7-Cre; SuFu ${ }^{-10 x P}$ cerebella at E18.5. G, $\boldsymbol{H}$, Gli3 expression is observed in all cell types and slightly weaker in the outer EGL (oEGL) compared with the inner EGL (iEGL) in control cerebellar at P6 (G). Gli3 is expressed ubiquitously in the cerebellum in Hoxb.7-Cre;SuFu ${ }^{-1 / 0 x P}$ mice at P6 (H). I, Western blot analysis of P7 cerebellar lysates reveals reduced levels of GLI1 and GLI2 and loss of the full-length (GLI3 ${ }^{190 \mathrm{kDa}}$ ) and truncated (GLI3 ${ }^{83 \mathrm{kDa}}$ ) forms of GLI3 in the absence of SUFU. 1-3, SuFu ${ }^{+/ 10 \times P} ; 4,5$, Hoxb.7-Cre; 5 UFu ${ }^{-10 \times P}$. Asterisks indicate background bands. Scale bar: (in $\boldsymbol{A}) \boldsymbol{A}-\boldsymbol{D}, 200 \mu \mathrm{m}$ (see also supplemental Fig. S3, available at www.jneurosci.org as supplemental material).

GLI activators were significantly reduced in P7 Hoxb.7-Cre; $\mathrm{SuFu} u^{-/ l o x P}$ cerebellar lysates compared with control samples (Fig. 7I). Interestingly, the level of GLI3R was barely detectable in the absence SUFU. These results indicate that SUFU positively regulates the levels of GLI activators and the generation of GLI3R.

\section{Restoring GLI3R rescues the SuFu-deficient phenotype}

To investigate the functional contribution of GLI3R in mediating the effects of $\mathrm{SuFu}$ on cerebellar morphogenesis, we generated mice that express GLI3R in the absence of SuFu. Using the Gli3 ${ }^{\Delta 699}$ knock-in allele, which results in a premature termination of Gli3 transcription and obligate expression of GLI3R (Böse et al., 2002), we increased the levels of GLI3R in Hoxb.7-Cre; $\mathrm{SuFu}{ }^{-/ l o x P}$ mutants (Hoxb.7-Cre;SuFu ${ }^{-/ l o x P} ; \mathrm{Gli}^{\Delta 699}$ ). Remark- ably, Hoxb.7-Cre;SuFu ${ }^{-/ l o x P ;}$ Gli $^{\Delta 699}$ mice displayed a body size comparable to that of control littermates and normal motor coordination (Fig. 8A,B). MRI analysis revealed that Hoxb.7-Cre; $\mathrm{SuFu}^{-/ l o x P}$; Gli3 ${ }^{\Delta 699}$ cerebella were largely normal in gross morphology and foliation and consisted of a vermis flanked by two hemispheres as seen in control cerebella (Fig. 8D,E). Histological analysis revealed a significant restoration of normal cytoarchitecture (Fig. $8 \mathrm{~F}-\mathrm{I}$ ). In contrast to Hoxb.7-Cre;SuFu ${ }^{-/ l o x P}$ cerebella (Fig. 2I,J), Hoxb.7-Cre;SuFu ${ }^{-/ l o x P} ; G_{l i 3}{ }^{\Delta 699}$ cerebella were characterized by foliation, albeit fewer folia, and the presence of distinct cell layers that were properly organized. However, rescue of patterning in $\mathrm{Hoxb}$.7-Cre;SuFu ${ }^{-1 l o x P}$;Gli3 ${ }^{\Delta 699}$ mice was not complete and small dysplastic regions were observed in variable locations throughout the cerebellum. In addition, analysis of 


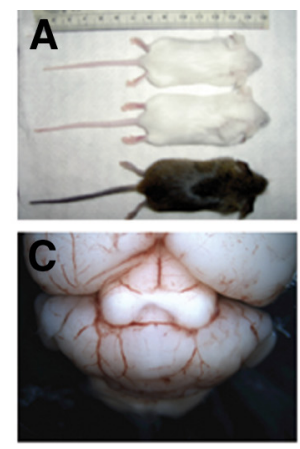

B

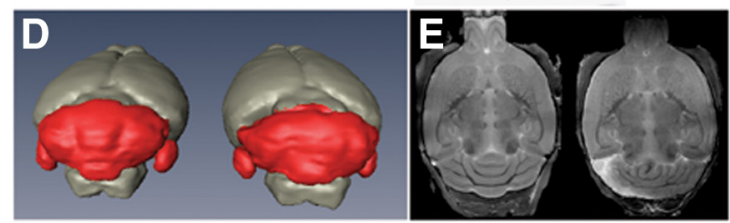

$\mathbf{F}$

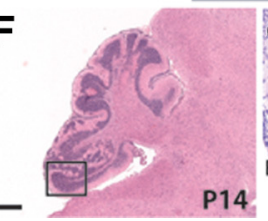

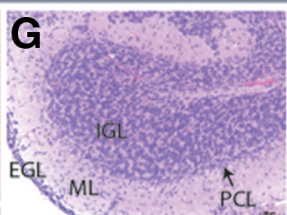
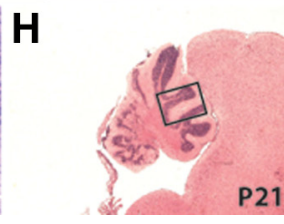

P21

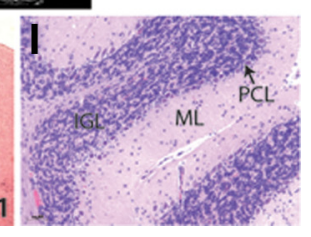

Figure 8. GLI3R significantly rescues reduced body size, abnormal cerebellar gross morphology and patterning defects. $\boldsymbol{A}$, Hoxb.7-Cre;SuFu ${ }^{-/ l o x P} ; G_{1 i}{ }^{\Delta 699}$ mutants (top) are comparable to control littermates (bottom two) in body size. B, Hoxb.7-Cre; $\mathrm{SuFu}^{-/ \text {IloxP }}$;Gli3 ${ }^{\Delta 699}$ mutants display normal motor coordination (Fig. 2C,D).C, A whole-mount image of a Hoxb.7-Cre;SuFu ${ }^{-/ l o x P}$; Gli3 ${ }^{\Delta 699}$ brain shows a rescue in cerebellar gross morphology, although distinct folia and demarcation between the vermis and hemispheres are not completely restored. D, E, MRI three-dimensional volume and slice images of control (left) and Hoxb.7-Cre; $\mathrm{SuFu}^{-1 / 0 \times P} ; \mathrm{Gli3}^{\Delta 699}$ (right) brains reveal significant restoration of normal cerebellar morphology by GLI3R. F-I, Severe patterning defects caused by loss of SUFU (Fig. $2 I-N$ ) are significantly rescued. All cell layers are clearly detected in Hoxb.7-Cre;SuFu ${ }^{-/ l o x P}$; Gli3 $^{\Delta 699}$ mutants and laminar organization is comparable to control cerebella at P14 and P21 $(G, I)$. Note that slightly abnormal cellular organization is detected in some regions. IGL, Inner granule layer; $M L$, molecular layer; PCL, Purkinje cell layer. Scale bars: (in $\boldsymbol{F}$ ) $\boldsymbol{C}, 2.5 \mathrm{~mm} ; \boldsymbol{F}, \boldsymbol{H}, 500 \mu \mathrm{m} ; \boldsymbol{G}, \boldsymbol{I}, 62.2 \mu \mathrm{m}$ (see also supplemental Fig. S4, available at www.jneurosci.org as supplemental material).

Hoxb.7-Cre;SuFu ${ }^{-/ l o x P} ;$ Gli3 $^{\Delta 699}$ embryos indicated a significant rescue of the mid-hindbrain patterning defects and delayed cerebellar formation during embryogenesis (supplemental Fig. S4A-F, available at www.jneurosci.org as supplemental material). These findings suggest that expression of GLI3R in the absence of SUFU can significantly rescue the morphological and patterning defects observed in Hoxb.7-Cre;SuFu ${ }^{-/ l o x P}$ mutants.

To characterize the effect of GLI3R restoration on cell differentiation, we analyzed expression of cell-specific markers. While calbindin staining was barely detectable in Hoxb.7-Cre;SuFu ${ }^{-/ l o x P}$ mutants and Purkinje cells lacked the characteristic dendritic morphology at P7, in Hoxb.7-Cre;SuFu ${ }^{-/ l o x P}$;Gli3 ${ }^{\Delta 699}$, calbindinpositive Purkinje cells were clearly present at P7. However, at this stage, Purkinje cells exhibited dendrites that were slightly less elaborate than control cerebella (Fig. $9 A-C$, green). Interestingly, by $\mathrm{P} 14$, Purkinje cells were indistinguishable from those observed in control cerebella and indeed, had matured at an earlier stage than that observed in Hoxb.7-Cre;SuFu ${ }^{-l l o x P}$ mutants (Fig. 9DI). Further, quantitative analysis demonstrated a significant decrease in the number of Purkinje cells in Hoxb.7-Cre;SuFu ${ }^{-/ l o x P}$ cerebella compared with control cerebella $\left({ }^{*} p=0.03\right)$ and restoration of normal Purkinje cell number in Hoxb.7-Cre;SuFu ${ }^{-/ l o x P}$; $\mathrm{Gli3}^{\Delta 699}$ cerebella (supplemental Fig. S2 B, available at www. jneurosci.org as supplemental material). In P7 Hoxb.7-Cre; $\mathrm{SuFu}^{-/ l o x P} ; \mathrm{Gli}^{\Delta 699}$ cerebella, expression of GFAP, a marker of Bergmann glia and astrocytes, was comparable to control cerebella whereas a significant downregulation was observed in Hoxb.7-Cre; $S u F u^{-/ l o x P}$ cerebella (Fig. 9A-C, red). By P14, properly aligned Berg-

\section{Discussion}

mann glia cell somas and radial fibers were present in Hoxb.7-Cre;SuFu ${ }^{-1 / \text { oxP }}$;Gli3 ${ }^{\Delta 699}$ mutants, although ectopic Bergmann glia cell somas were located in the inner granule layer as revealed by BLBP staining (Fig. 9F, I,L). In contrast, Hoxb.7-Cre;SuFu ${ }^{-/ l o x P}$ Bergmann glia exhibited abnormal cell body organization characterized by a failure to align with Purkinje cells, and defective radial fibers at P14 and P21, indicating a rescue of the defective cell differentiation by GLI3R (Fig. 9E, $H, K$ ). Double staining of PAX6 and NeuN, markers of immature migrating granule cells and mature granule cells, respectively, revealed that at P14, expression of both markers in Hoxb.7-Cre; $\mathrm{SuFu}^{- \text {/loxP }}$; Gli3 ${ }^{\Delta 699}$ cerebella was comparable to control cerebella (Fig. 9J,L). Expression of PAX6 was upregulated in the inner granule layer of Hoxb.7-Cre;SuFu ${ }^{-/ l o x P} ;$ Gli3 $^{\Delta 699}$ mutants compared with control cerebella, suggesting a slight increase in the proportion of cells in the inner granule layer that were not fully mature. In contrast, PAX6 expression was significantly enhanced in the presumptive EGL of Hoxb.7-Cre;SuFu-/loxP cerebella, which resulted in a marked proportional decrease in the number of NeuNexpressing mature granule cells (Fig. 9K). By P21, however, immature granule cells had eventually differentiated and all granule cells expressed NeuN in Hoxb.7-Cre;SuFu ${ }^{-1}$ loxp cerebella (supplemental Fig. S5A-C, available at www.jneurosci.org as supplemental material). In addition, a significant rescue of organization of PAX6-expressing cells in the EGL and upregulation of $\mathrm{PAX} 2$-expressing GABAergic interneuron precursors was observed in Hoxb.7-Cre;SuFu ${ }^{-1 l o x P} ; \mathrm{Gli3}^{\Delta 699}$ mutants during embryogenesis (supplemental Fig. S4G,H, available at www. jneurosci.org as supplemental material). Together, these data indicate that restoration of GLI3R in the absence of SUFU significantly rescues the abnormal cell differentiation of all major cell types observed in SuFu-deficient cerebella.

While the essential role of $S u F u$ during mammalian development has been clearly demonstrated in SuFu germline knock-out mice, the functions of $S u F u$ in the development of specific tissues after E9.5, the time point at which $S u F u$-null embryos die, remain unknown. By generating conditional knock-out mice in which $\mathrm{SuFu}$ deficiency is targeted to the cerebellum and some parts of the midbrain, we have uncovered novel functions of $S u F u$ and $\mathrm{SHH}$ signaling in cerebellar morphogenesis. Collectively, our findings suggest that (1) $S u F u$ is required for proper midhindbrain patterning, (2) $S u F u$ controls cerebellar patterning by regulating cell differentiation and migration, (3) SuFu regulates the localization and level of SHH signaling and the levels of GLIs, GLI3R in particular, and (4) GLI3R partially mediates $S u F u$ functions during cerebellar morphogenesis.

Our analyses show that the striking cerebellar dysplasia observed in postnatal Hoxb.7-Cre;SuFu ${ }^{- \text {lloxP }}$ cerebella is associated with defective mid-hindbrain patterning. The expression domain of $F g f 8$ is shifted anteriorly and overlaps with that of $O t \times 2$ in the 
absence of $S u F u$, whereas the two expression domains are mutually exclusive with clear boundaries in wild-type embryos. This finding suggests that while the specification of the midbrain remains intact in the absence of $S u F u$, the anterior shift of the isthmus is the probable cause of the aberrant mid-hindbrain patterning in mutant mice. Previous studies suggest that the dose of FGF8 released in the isthmus is critical to the mechanism by which different regions of the mid-hindbrain are induced. Two of the various FGF8 protein isoforms, FGF8a and FGF8b, are known to be expressed in the isthmus (Blunt et al., 1997; Sato et al., 2001). FGF8b induces cerebellar tissue whereas FGF8a induces midbrain structures (Lee et al., 1997; Liu et al., 1999, 2003; Sato et al., 2001). Moreover, mutants that express low levels of FGF8 only develop the superior colliculus and lateral cerebellum structures (Chi et al., 2003). Thus, in light of the finding that the source of FGF8 signaling is shifted further away from the presumptive cerebellar primordium in Hoxb.7-Cre;SuFu ${ }^{-/ l o x P}$ mutants, it is likely that levels of FGF8 are reduced in comparison with wild-type tissue. This can result in a prolonged period of time for a sufficient amount of FGF8 protein to accumulate and diffuse posteriorly and induce cerebellum tissue, causing delayed formation of the cerebellar primordium. Also, an expanded domain of FGF8 signaling activity between the isthmus and the presumptive cerebellum likely results in an enlarged hindbrain, consistent with the expanded isthmic tissue between the midbrain and the cerebellum seen in Hoxb.7-Cre;SuFu ${ }^{-/ l o x P}$ mutants. However, since we did not observe induction of cerebellum tissue in the region immediately adjacent to the shifted isthmus, it is unlikely that the level of FGF8 signaling is the only factor that determines specification of the cerebellum. Expression of specific genes before activation of FGF8 signaling in the isthmus may predetermine a cerebellar fate. Once the isthmus has been established, a proper level of FGF8 signaling may be required for the neuroepithelium of a cerebellar fate to be specified and differentiate into cerebellar precursors.

Although the role of $S u F u$ in mid-hindbrain development has never been investigated previously, GLI3R has been implicated in regulation of $F g f 8$ expression. Also, numerous studies suggest an essential role for SUFU in generation and/or promotion of GLI3R (Cheng and Bishop, 2002; Svärd et al., 2006; Kise et al., 2009). GLI3R is required for proper restriction of $F g f 8$ expression and tissue growth in the mid-hindbrain (Aoto et al., 2002). Our data indicate that GLI3R is undetectable in the absence of SUFU and restoration of GLI3R can partially rescue the abnormal midhindbrain patterning observed in Hoxb.7-Cre;SuFu ${ }^{- \text {loxP }}$ embryos.

P21

P14

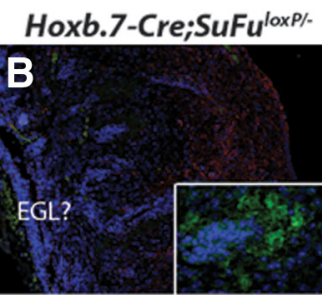

Hoxb.7-Cre;SuFuloxP/;Gli3 ${ }^{\Delta 699}$
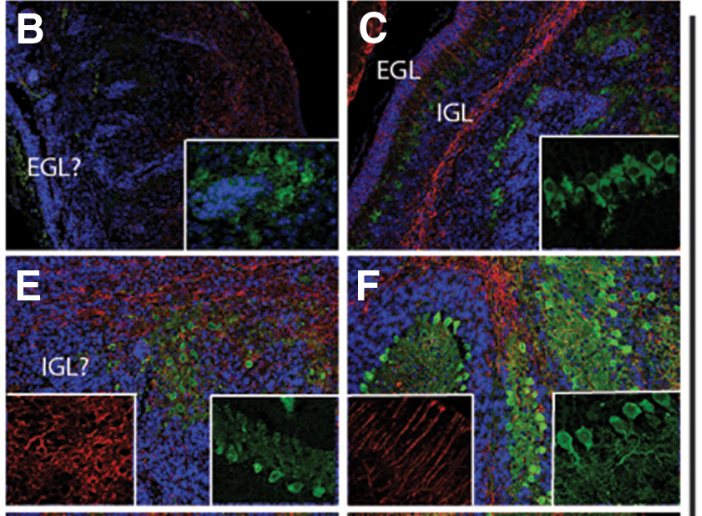

Figure 9. GLI3R rescues delayed cell differentiation in SuFu-deficient cerebella. $\boldsymbol{A}-\boldsymbol{I}$, Calbindin staining (green) reveals a complete restoration of normal Purkinje cell morphology in Hoxb.7-Cre;SuFu ${ }^{-1 / 0 \times P}$; Gli ${ }^{\Delta 699}$ cerebella by P14 (C, F). Hoxb.7-Cre; $\mathrm{SuFu}^{- \text {IloxP }}$ Purkinje cells show decreased calbindin expression and are abnormal in dendritic morphology at P7 and P14 (B, E). By P21, Purkinje cells in Hoxb.7-Cre;SuFu ${ }^{-10 x P}$ cerebella are comparable to those observed in control and Hoxb.7-Cre;SuFu-110xP, $\mathrm{Gli}^{\Delta 699}$ cerebella (G-I). GFAP expression (red), a marker of Bergmann glia, in Hoxb.7-Cre;SuFu ${ }^{-1 / 0 \times P} ;$; Gli3 ${ }^{\Delta 699}$ cerebella is comparable to that observed in control cerebella as early as $P 7(C, F, I)$. In Hoxb.7-Cre;SuFu ${ }^{-10 \times P}$ mutants, Bergmann glia are severely disorganized and radial fibers are misaligned $(\boldsymbol{B}, \boldsymbol{E}, \boldsymbol{H}) . \mathbf{J}-\boldsymbol{L}$, BLBP-positive Bergmann glia cell somas (white arrowheads) are severely disorganized and fail to alight with Purkinje cells (yellow asterisks) in Hoxb.7-Cre;SuFu-1loxP cerebella. Normal Bergmann glia organization is restored with the exception of some Bergmann glia cell somas that are detected in the inner granule layer (IGL) in Hoxb.7-Cre;SuFu ${ }^{-110 \times P}$;Gli ${ }^{\Delta 699}$ cerebella. M-0, PAX6 and NeuN double staining demonstrates normal expression of the granule cell markers in Hoxb.7-Cre;SuFu ${ }^{-10 x P} ;$ Gli3 ${ }^{\Delta 699}$ cerebella (L). Note that PAX6 expression is slightly upregulated in the IGL of Hoxb.7-Cre;SuFu ${ }^{-10 \times P} ;$ Gli $^{\Delta 699}$ cerebella. In Hoxb.7-Cre;SuFu ${ }^{-1 l o x P}$ cerebella, the proportion of PAX6-expressing cells in the presumptive EGL to NeuN-expressing cells in the IGL is significantly increased compared with control and Hoxb.7-Cre;SuFu-IoxP, Gli ${ }^{\Delta 699}$ cerebella (K). ML, Molecular layer. Scale bars: (in $\left.\mathbf{G}\right) \boldsymbol{A}-\boldsymbol{I}, 200 \mu \mathrm{m}$; $\boldsymbol{J}-\mathbf{L}, 100 \mu \mathrm{m}$; (in $\boldsymbol{M}$ ) $\boldsymbol{M}-\mathbf{0}, 200 \mu \mathrm{m}$ (see also supplemental Figs. S4, S5, available at www.jneurosci.org as supplemental material).

This indicates that GLI3R mediates some of the $S u F u$ functions during mid-hindbrain specification. However, we observe a shift in Fgf8 expression rather than an expansion as observed in Gli3-null mutants (Blaess et al., 2008). This novel finding suggests an additional function of $\mathrm{SuFu}$ distinct from GLI3R during mid-hindbrain patterning. Also, Hoxb.7-Cre;SuFu ${ }^{-/ l o x P}$ mutants exhibit anterior-posterior patterning defects rather than the tissue overgrowth or exencephaly observed in Hoxb.7-Cre;Ptc1 ${ }^{-/ l o x P}$ mutants caused by ligand-independent activation of SHH signaling. Since Hoxb.7-Cre; $P t c 1^{-/ l o x P}$ mutants lack apparent mid-hindbrain defects and exhibit normal timing of cerebellar formation, the function of Ptc1 is likely limited to controlling cell proliferation by constitutively suppressing 
$\mathrm{SHH}$ activity in the low $\mathrm{SHH}$ region of the neural tube. Thus, $\mathrm{SuFu}$ likely plays a role that is distinct from that of GLI3R or Ptc1 by regulating the localization of $F g f 8$ expression during mid-hindbrain patterning. It is presently unknown whether SUFU has $\mathrm{HH}$ signaling-independent functions, if any, and to what extent GLI3R mediates SUFU functions during mid-hindbrain development.

A theme common to all cell lineages investigated here is a delay in specification and differentiation in the absence of SuFu. The fact that a delay in differentiation is observed regardless of the cell type indicates that $S u F u$ plays a role in all cerebellar precursors in determining the timing of specification. Delayed cerebellar specification during mid-hindbrain patterning caused by aberrant $F g f 8$ expression in the absence of $S u F u$ may in turn delay the transition of neuroepithelial cells to cerebellar neural precursors, resulting in delayed differentiation into lineage-specific precursors. Our data show that SUFU is normally expressed in radial glia precursors along the ventricular zone in vivo. In vitro data demonstrated enhanced gliogenesis versus neurogenesis in the absence of SUFU, suggesting that SUFU in radial glia precursors functions to promote neuronal differentiation during early stages of cerebellar morphogenesis. It is also possible that $\mathrm{SuFu}$ coordinates the timing of expression of genes that promote differentiation in a coordinate manner. Extensive coordination and interactions between cell types during cerebellar morphogenesis have been described in depth. In particular, it is known that migration of Purkinje cells and Bergmann glia are closely correlated in a spatial and temporal manner. Thus, defective timing of differentiation of one or more cell types can have a global negative impact on differentiation and migration of other cell types, and ultimately, on cerebellar patterning. Intriguingly, this also raises the question whether $S u F u$ controls differentiation in all cerebellar cell types or the abnormal differentiation in all major cell types observed in Hoxb.7-Cre;SuFu ${ }^{-1 l o x P}$ mutants is a result of noncell-autonomous effects of $S u F u$ deletion. Further investigation using cell lineage-specific deletion of $S u F u$ is needed to determine the cell-autonomous effects of $S u F u$.

The phenotype we observe in Hoxb.7-Cre;SuFu ${ }^{-/ l o x P}$ mutants is similar to that in mice with primary defects in radial glia. Pten conditional knock-out in the cerebellum leads to cerebellar mispatterning, severe disorganization and abnormal morphology of Bergmann glia and granule cell migration defects (Yue et al., 2005). Targeted deletion of Fgf9 results in abnormal Bergmann glia scaffold formation, impaired granule cell migration and defective Purkinje cell maturation, as observed in SuFu-deficient cerebella (Lin et al., 2009). The defects observed in Pten and Fgf9 mutant mice suggest that abnormal Bergmann glia differentiation may be a primary cause of the dysplasia observed in Hoxb.7$\mathrm{Cre} ; \mathrm{SuFu} u^{-1 \text { loxP }}$ mice.

SHH signaling has been extensively studied in the context of cerebellar development for its role in medulloblastoma as well as during normal cerebellar morphogenesis (Goodrich et al., 1997; Dahmane and Ruiz i Altaba, 1999; Kenney et al., 2003; Corrales et al., 2004, 2006; Lewis et al., 2004; Yang et al., 2008). In Hoxb.7$\mathrm{Cre} ; \mathrm{SuFu} u^{-/ l o x P}$ cerebella, the misexpression and absence of Shh in the external granule layer and the Purkinje cell layer, respectively, suggests that abnormal or delayed differentiation of Purkinje cells likely leads to a failure of Purkinje cells to provide $\mathrm{SHH}$ signaling to granule cell precursor at the right time. The upregulation and misexpression of Shh in granule cell precursors in Hoxb.7-Cre;SuFu $u^{-/ l o x P}$ mice may reflect the effect of ligandindependent activation of $\mathrm{SHH}$ signaling in the absence of SUFU-mediated negative regulation of the pathway. Further, the essential loss of GLI3R and the presence of full-length GLI activators in $\mathrm{Hoxb} .7-\mathrm{Cre} ; \mathrm{SuFu}{ }^{-/ l o x P}$ cerebellar protein lysates suggests that GLI activator activity may be exaggerated as enhanced SHH signaling activity due to the increased GLI activator to repressor ratio. These results are consistent with a recent study that demonstrated a role for SUFU in stabilizing GLI activator proteins (Chen et al., 2009). Intriguingly, the rescue of the SuFudeficient cerebellar phenotype by GLI3R indicates that GLI3R, unlike GLI activators, does not require SUFU for stabilization, consistent with a recent study that in which the $S u F u^{-/-}$neural tube phenotype was rescued by homozygous expression of Gli3 $^{\Delta 699}$ (Wang et al., 2010). The apparent dual and complex functions of SUFU in the $\mathrm{HH}$ signaling pathway are likely context-dependent, and further investigation is required to gain better insights into the mechanism by which SUFU regulates $\mathrm{HH}$ signaling.

Our studies reveal novel and essential roles for SuFu during mid-hindbrain specification and cerebellar morphogenesis. Data shown here demonstrate that $S u F u$ is a key regulator of midhindbrain patterning, cerebellar cell differentiation, and $\mathrm{SHH}$ signaling. We show that GLI3R acts as a downstream effector to mediate the functions of $\mathrm{SuFu}$ during cerebellar morphogenesis. These results provide a basis for further investigation of the autonomous functions of $S u F u$ during mid-hindbrain patterning, lineage-specific cell differentiation, and cell-cell interactions during development of the cerebellum.

\section{References}

Aoto K, Nishimura T, Eto K, Motoyama J (2002) Mouse GLI3 regulates Fgf8 expression and apoptosis in the developing neural tube, face, and limb bud. Dev Biol 251:320-332.

Barnfield PC, Zhang X, Thanabalasingham V, Yoshida M, Hui CC (2005) Negative regulation of Gli1 and Gli2 activator function by Suppressor of fused through multiple mechanisms. Differentiation 73:397-405.

Blaess S, Corrales JD, Joyner AL (2006) Sonic hedgehog regulates Gli activator and repressor functions with spatial and temporal precision in the mid/hindbrain region. Development 133:1799-1809.

Blaess S, Stephen D, Joyner AL (2008) Gli3 coordinates three-dimensional patterning and growth of the tectum and cerebellum by integrating Shh and Fgf8 signaling. Development 135:2093-2103.

Blunt AG, Lawshé A, Cunningham ML, Seto ML, Ornitz DM, MacArthur CA (1997) Overlapping expression and redundant activation of mesenchymal fibroblast growth factor (FGF) receptors by alternatively spliced FGF-8 ligands. J Biol Chem 272:3733-3738.

Böse J, Grotewold L, Rüther U (2002) Pallister-Hall syndrome phenotype in mice mutant for Gli3. Hum Mol Genet 11:1129-1135.

Cain JE, Islam E, Haxho F, Chen L, Bridgewater D, Nieuwenhuis E, Hui CC, Rosenblum ND (2009) GLI3 repressor controls nephron number via regulation of Wnt11 and Ret in ureteric tip cells. PLoS One 4:e7313.

Chen MH, Wilson CW, Li YJ, Law KK, Lu CS, Gacayan R, Zhang X, Hui CC, Chuang PT (2009) Cilium-independent regulation of Gli protein function by Sufu in Hedgehog signaling is evolutionarily conserved. Genes Dev 23:1910-1928.

Cheng SY, Bishop JM (2002) Suppressor of Fused represses Gli-mediated transcription by recruiting the SAP18-mSin 3 corepressor complex. Proc Natl Acad Sci U S A 99:5442-5447.

Chi CL, Martinez S, Wurst W, Martin GR (2003) The isthmic organizer signal FGF8 is required for cell survival in the prospective midbrain and cerebellum. Development 130:2633-2644.

Corrales JD, Rocco GL, Blaess S, Guo Q, Joyner AL (2004) Spatial pattern of sonic hedgehog signaling through Gli genes during cerebellum development. Development 131:5581-5590.

Corrales JD, Blaess S, Mahoney EM, Joyner AL (2006) The level of sonic hedgehog signaling regulates the complexity of cerebellar foliation. Development 133:1811-1821.

Dahmane N, Ruiz i Altaba A (1999) Sonic hedgehog regulates the growth and patterning of the cerebellum. Development 126:3089-3100.

Ellis T, Smyth I, Riley E, Graham S, Elliot K, Narang M, Kay GF, Wicking C, 
Wainwright B (2003) Patched 1 conditional null allele in mice. Genesis 36:158-161.

Fuccillo M, Joyner AL, Fishell G (2006) Morphogen to mitogen: the multiple roles of hedgehog signalling in vertebrate neural development. Nat Rev Neurosci 7:772-783.

Goodrich LV, Milenković L, Higgins KM, Scott MP (1997) Altered neural cell fates and medulloblastoma in mouse patched mutants. Science 277:1109-1113.

Kenney AM, Cole MD, Rowitch DH (2003) Nmyc upregulation by sonic hedgehog signaling promotes proliferation in developing cerebellar granule neuron precursors. Development 130:15-28.

Kise Y, Morinaka A, Teglund S, Miki H (2009) Sufu recruits GSK3beta for efficient processing of Gli3. Biochem Biophys Res Commun 387:569-574.

Kogerman P, Grimm T, Kogerman L, Krause D, Undén AB, Sandstedt B, Toftgård R, Zaphiropoulos PG (1999) Mammalian suppressor-of-fused modulates nuclear-cytoplasmic shuttling of Gli-1. Nat Cell Biol 1:312-319.

Lee SM, Danielian PS, Fritzsch B, McMahon AP (1997) Evidence that FGF8 signalling from the midbrain-hindbrain junction regulates growth and polarity in the developing midbrain. Development 124:959-969.

Lee Y, Kawagoe R, Sasai K, Li Y, Russell HR, Curran T, McKinnon PJ (2007) Loss of suppressor-of-fused function promotes tumorigenesis. Oncogene 26:6442-6447.

Lewis PM, Gritli-Linde A, Smeyne R, Kottmann A, McMahon AP (2004) Sonic hedgehog signaling is required for expansion of granule neuron precursors and patterning of the mouse cerebellum. Dev Biol 270: 393-410.

Lin Y, Chen L, Lin C, Luo Y, Tsai RY, Wang F (2009) Neuron-derived FGF9 is essential for scaffold formation of Bergmann radial fibers and migration of granule neurons in the cerebellum. Dev Biol 329:44-54.

Liu A, Losos K, Joyner AL (1999) FGF8 can activate Gbx2 and transform regions of the rostral mouse brain into a hindbrain fate. Development 126:4827-4838

Liu A, Li JY, Bromleigh C, Lao Z, Niswander LA, Joyner AL (2003) FGF17b and FGF18 have different midbrain regulatory properties from FGF8b or activated FGF receptors. Development 130:6175-6185.

Mo R, Freer AM, Zinyk DL, Crackower MA, Michaud J, Heng HH, Chik KW, Shi XM, Tsui LC, Cheng SH, Joyner AL, Hui C (1997) Specific and redundant functions of Gli2 and Gli3 zinc finger genes in skeletal patterning and development. Development 124:113-123.

Préat T (1992) Characterization of Suppressor of fused, a complete suppressor of the fused segment polarity gene of Drosophila melanogaster. Genetics 132:725-736.

Sato T, Araki I, Nakamura H (2001) Inductive signal and tissue responsiveness defining the tectum and the cerebellum. Development 128:2461-2469.

Soriano P (1999) Generalized lacZ expression with the ROSA26 Cre reporter strain. Nat Genet 21:70-71.

Svärd J, Heby-Henricson K, Persson-Lek M, Rozell B, Lauth M, Bergström A, Ericson J, Toftgård R, Teglund S (2006) Genetic elimination of Suppressor of fused reveals an essential repressor function in the mammalian Hedgehog signaling pathway. Dev Cell 10:187-197.

Taylor MD, Liu L, Raffel C, Hui CC, Mainprize TG, Zhang X, Agatep R, Chiappa S, Gao L, Lowrance A, Hao A, Goldstein AM, Stavrou T, Scherer SW, Dura WT, Wainwright B, Squire JA, Rutka JT, Hogg D (2002) Mutations in SUFU predispose to medulloblastoma. Nat Genet 31:306-310.

Wang C, Pan Y, Wang B (2010) Suppressor of fused and Spop regulate the stability, processing and function of Gli2 and Gli3 full-length activators but not their repressors. Development 137:2001-2009.

Yang ZJ, Ellis T, Markant SL, Read TA, Kessler JD, Bourboulas M, Schüller U, Machold R, Fishell G, Rowitch DH, Wainwright BJ, Wechsler-Reya RJ (2008) Medulloblastoma can be initiated by deletion of Patched in lineage-restricted progenitors or stem cells. Cancer Cell 14:135-145.

Yue Q, Groszer M, Gil JS, Berk AJ, Messing A, Wu H, Liu X (2005) PTEN deletion in Bergmann glia leads to premature differentiation and affects laminar organization. Development 132:3281-3291.

Zhao H, Kegg H, Grady S, Truong HT, Robinson ML, Baum M, Bates CM (2004) Role of fibroblast growth factor receptors 1 and 2 in the ureteric bud. Dev Biol 276:403-415. 